\title{
True density of combustion emitted particles: A comparison of results highlighting the influence of the organic contents
}

\author{
F.-X. Ouf ${ }^{1}$, S. Bourrous ${ }^{1}$, S. Fauvel ${ }^{1}$, A. Kort ${ }^{1,2}$, L. Lintis ${ }^{1,3}$, J. Nuvoli ${ }^{1,3}$ and J. Yon ${ }^{4}$ \\ ${ }^{1}$ Institut de Radioprotection et de Sûreté Nucléaire (IRSN), PSN-RES, SCA, Gif-Sur-Yvette, 91192, France. \\ ${ }^{2}$ Ecole Nationale Supérieure des Mines, SPIN-EMSE, CNRS:UMR5307, LGF, 42023 Saint-Etienne, France \\ ${ }^{3}$ Université de Lorraine, Laboratoire Réactions et Génie des Procédés (LRGP), UMR 7274, F-54000, Nancy,
} France.

${ }^{4}$ Normandie Université, INSA Rouen, UNIROUEN, CNRS, CORIA, 76000 Rouen, France.

\begin{abstract}
$\underline{\text { Abstract }}$
A validation of the ISO 787-23 method for measuring true density on reference black carbon samples and combustion emitted particles is proposed and compared to alternative methods. New measurements of true density on samples representative of fire emissions at different scales are presented and discussed, according to their respective experimental uncertainties. These results are compared to the values of soot true densities reported in the literature. An interesting correlation between the true density of combustion emitted particles and the Organic Carbon (OC) content is observed and commented: the true density significantly decreases as OC content increases. Three different ranges of true densities are then proposed as a function of the OC/Total Carbon (TC) ratio of combustion emitted particles. For low OC contents (i.e. below 5\%) and high OC contents (i.e. above 20\%), respective mean values of $1834+/-187 \mathrm{~kg} / \mathrm{m}^{3}$ and $1285+/-217 \mathrm{~kg} / \mathrm{m}^{3}$ are proposed. For intermediate OC content values, a fit is applied based on a mixing law. Finally, there is a discussion on the relevance of using these values for true densities of combustion emitted particles for temperatures representative of those reported in industrial fires, ranging from $25^{\circ} \mathrm{C}$ to $240^{\circ} \mathrm{C}$.
\end{abstract}

\section{$\underline{\text { Introduction }}$}

True density is the density of the condensed material as opposed to the effective density (density of porous particles or agglomerates/aggregates of nanoparticles, McMurry, Wang, Park, \& Ehara, 2002). For aggregates of primary spheres, true density refers to the density of the primary spheres. For soot particles, defined by Petzold et al. (2013) as agglomerates of monomers consisting solely of carbon with small amounts of hydrogen and oxygen, true density of primary particles is generally assumed to be lower than graphite density of $2200 \mathrm{~kg} / \mathrm{m}^{3}$ due to a less dense microstructure. True density of powders has been widely measured since the last century using Helium pycnometry ${ }^{1}$ and volume displacement methods such as ISO $787-23^{2}$. In most cases, with these methods, at least $500 \mathrm{mg}$ of powder is needed to perform a relevant density analysis. This kind of analysis is suitable for industrial applications in the field of powder production, for which powder quantity is not a limiting factor. For research applications, and specifically within the aerosol and soot scientific community, retrieving several hundred milligrams of nanostructured carbonaceous particles from a burner, a diffusion flame or automotive/aircraft engines is a tremendous task. Nevertheless, beyond these experimental limitations, soot true density is an important property of such particles since it is needed for many measurement techniques (light extinction (Choi et al., 1995), laser induced incandescence (Michelsen et al., 2007), morphological analysis according to effective density measurement and computation of mass concentration according to size distribution measurement devices (Yon et al., 2015)) and for describing their physical behavior (cake formation during filtration processes, see Thomas et al., 2014, and soot formation prediction, see Kennedy, 1997). Furthermore, this parameter has been recently used for the development of an automatic analysis software (Bourrous et al., 2018) able to determine the specific surface area of soot samples directly from their TEM images.

\footnotetext{
${ }^{1}$ https://www.astm.org/Standards/B923.htm

2 https://www.iso.org/standard/5102.html
} 
Usually, the true density of freshly emitted soot particles is assumed to be close to $1800-1900 \mathrm{~kg} / \mathrm{m}^{3}$ (Bond et al., 2013; Dobbins, Mulholland, \& Bryner, 1994). In fact, due to the lack of sample mass, limited numbers of experimental values are reported in the literature and they are often determined by Helium pycnometry (Roessler \& Faxvog, 1980). Recently, several authors have proposed coupling a differential mobility analyzer (DMA) with a mass to mobility classifier (e.g. the Aerosol Particle Mass APM analyzer (Ehara et al., 1996) to the Centrifugal Particle Mass Analyzer CPMA (J. S. Olfert \& Collings, 2005)) for computing the inherent density of diesel (Park et al., 2004) or propane/air soot (Yon et al., 2015). However, these new approaches are indirect measurement methods and need validation.

The aim of the present paper is to review values of soot true density reported in the literature and to propose additional values for particles emitted from materials relevant to fire emission studies at several scales. The reported values are mainly obtained using the ISO 787-23 method. DMA-CPMA approach was preferred for samples whose required mass cannot be reasonably obtained. The influence of the organic content of combustion emitted particles is then demonstrated, showing a significant decrease in true density as OC content increases. Finally, reference densities are proposed for low (less than 5\%) and high (more than 20\%) OC content of combustion emitted particles.

\section{Experimental method and validation}

The ISO 787-23 method is based on measurement of the liquid displacement induced by the immersion of a known mass of powder. The mass-to-volume ratio of the analyzed particles is determined by means of Archimedes thrust. A sketch of the principle and the measurement procedure is presented in Figure 1.

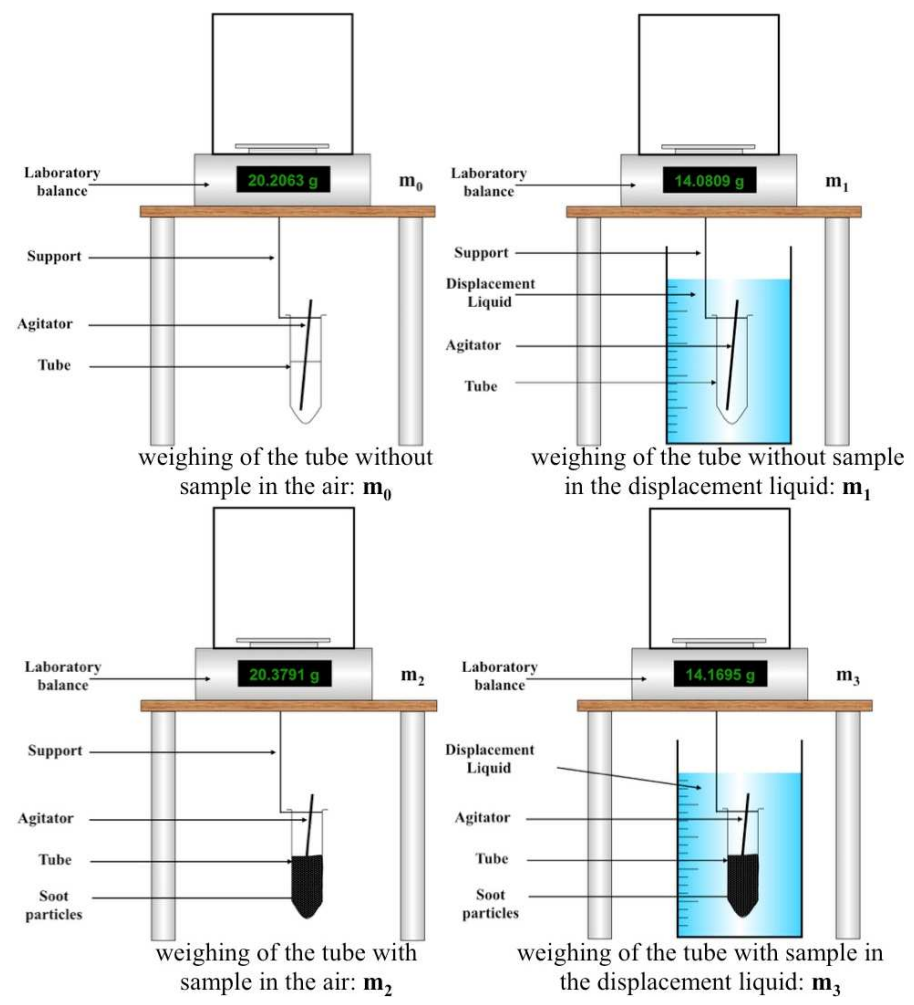

Figure 1: experimental protocol of powder true density measurement according to ISO 787-23

Four weighings (using a Mettler Toledo AE 240 analytical balance with a considered resolution of $0.001 \mathrm{~g}$ ) are carried out: two in the air and two in the displacement liquid. Ethanol is used as the displacement liquid; its reference density at $20^{\circ} \mathrm{C}$ is $789 \mathrm{~kg} / \mathrm{m}^{3}(\mathrm{CRC}, 2002)$. The first two weighings are of the sampling tube while the next two are of the sampling tube plus the powder sample. The measurements in the air determine the mass of powder while the measurements in ethanol give its volume. Due to the high porosity of nanostructured powders, it is necessary to compact the sample as much as possible. For this purpose, high-speed centrifugation (3000 
RPM) is applied for 15 minutes to the samples immerged in the displacement liquid. The measurement protocol is based on the 7 following steps:

- weighing of the tube without sample in the air: $\mathbf{m}_{\mathbf{0}}$,

- $\quad$ weighing of the tube without sample in the displacement liquid: $\mathbf{m}_{\mathbf{1}}$,

- drying of the tube and filling of $1 / 2$ of the tube with the sample,

- weighing of the tube with sample in the air: $\mathbf{m}_{2}$,

- $\quad$ filling of $3 / 4$ of the tube with the displacement liquid,

- $\quad$ high-speed centrifugation (3000 RPM) for 15 minutes,

- $\quad$ weighing of the tube with sample in the displacement liquid: $\mathbf{m}_{3}$.

Sample true density $\left(\rho_{\text {sample }}\right)$ is defined as the ratio of the sample mass $\left(\mathrm{m}_{\text {sample }}\right)$ to the sample volume $\left(\mathrm{V}_{\text {sample }}\right)$ :

$$
\rho_{\text {sample }}=\frac{m_{\text {sample }}}{V_{\text {sample }}}
$$

The sample mass $\left(\mathrm{m}_{\text {sample }}\right)$ is determined by weighing the tube in the air, with and without the sample:

$$
\mathrm{m}_{\text {sample }}=\mathrm{m}_{2}-\mathrm{m}_{0}
$$

The volume of the sample is determined by weighing the tube in the displacement liquid, with and without the sample. The difference between these two masses is associated with the liquid displacement induced by the Archimedes thrust applied by the liquid to the volume of the sample.

First, the displacement associated with the volume of the tube $\left(\mathrm{V}_{\text {tube }}\right)$ must be determined by weighing the empty tube in the air $\left(\mathrm{m}_{0}\right)$ and in the displacement liquid $\left(\mathrm{m}_{1}\right)$. The following relationship can be then considered:

$$
\mathrm{m}_{1}=\mathrm{m}_{0}-\mathrm{V}_{\text {tube }} \cdot \rho_{\text {eth }}
$$

The density of the displacement liquid $\left(\rho_{\text {eth }}\right)$, i.e. ethanol, is then computed at the measurement temperature T (expressed in ${ }^{\circ} \mathrm{C}$ ), considering the reference ethanol density $\rho_{0}$ equal to $806.34 \mathrm{~kg} / \mathrm{m}^{3}$ at $0{ }^{\circ} \mathrm{C}$ and applying a linear fit to the data reported in Dean (1990):

$$
\rho_{\text {eth }}=-0.8462 \mathrm{~T}+\rho_{0}
$$

Then, the displacement induced by the volume of sample in the tube can be determined by weighing the system (tube + sample) in the air $\left(\mathrm{m}_{2}\right)$ and in ethanol $\left(\mathrm{m}_{3}\right)$.

$$
\mathrm{m}_{3}=\mathrm{m}_{2}-\left(\mathrm{V}_{\text {tube }}+\mathrm{V}_{\text {sample }}\right) \cdot \rho_{\mathrm{eth}}=\mathrm{m}_{2}-\mathrm{V}_{\text {tube }} \cdot \rho_{\mathrm{eth}}-\mathrm{V}_{\text {sample }} \cdot \rho_{\mathrm{eth}}
$$

According to equations (3) and (5), the mass $\mathrm{m}_{3}$ is defined as:

$$
\mathrm{m}_{3}=\mathrm{m}_{2}-\left(\mathrm{m}_{0}-\mathrm{m}_{1}\right)-\mathrm{V}_{\text {sample }} \cdot \rho_{\mathrm{eth}}
$$

The volume of the sample is determined by:

$$
\mathrm{V}_{\text {sample }}=\frac{\mathrm{m}_{2}-\mathrm{m}_{3}-\mathrm{m}_{0}+\mathrm{m}_{1}}{\rho_{\mathrm{eth}}}
$$

Finally, the sample density is defined by:

$$
\rho_{\text {sample }}=\frac{m_{\text {sample }}}{V_{\text {sample }}}=\frac{\left(m_{2}-m_{0}\right) \cdot \rho_{\text {eth }}}{m_{2}-m_{3}-m_{0}+m_{1}}=\frac{\left(m_{2}-m_{0}\right) \cdot \rho_{\text {eth }}}{\left(m_{2}-m_{0}\right)-\left(m_{3}-m_{1}\right)}=\frac{\rho_{\text {eth }}}{1-\frac{\left(m_{3}-m_{1}\right)}{\left(m_{2}-m_{0}\right)}}
$$

In the present study, sample densities were determined $\mathrm{N}$ times and a $\chi^{2}$ test was carried out for each sample in order to discuss the dispersion of the experimental results. This dispersion is estimated by using the standard 
deviation $\mathrm{s}\left(\rho_{\text {sample }}\right)$, according to the mean values of the uncertainties $\mathrm{u}\left(\rho_{\text {sample }}\right)$. Finally, the mean value of sample density $\bar{\rho}_{\text {sample }}$ is determined by considering the $\mathrm{N}$ values obtained, and the uncertainties associated with this mean value are computed (for details see Annex I):

$$
\overline{\rho_{\text {sample }}}=\frac{1}{\mathrm{~N}} \sum_{\mathrm{i}=1}^{\mathrm{N}} \rho_{(\mathrm{i}) \text { sample }}
$$

Before it was applied to real soot particles, this method was validated on several powder samples and carbonaceous particles with well-known true densities considered in the present article as "references". Table 1 presents the properties of the reference samples and Figure 2 presents the comparison between currently measured densities based on the ISO 787-23 method and the reference true densities corresponding to the values reported in the literature. At least three density measurements were made for each reference sample, and their mean values are presented in Table 1 . As previously mentioned, before computing the mean values, a $\chi^{2}$ test was also applied to the density results in order to verify the dispersion of the experimental values. This dispersion is explained by the experimental measurement process (see Annex II). The agreement between measured and reference densities appears to be quasi-perfect with a discrepancy of less than 5\%. This confidence interval is in good agreement with the uncertainty determined for the entire measurement protocol and detailed in Annex I.

Table 1: properties of reference samples used for the validation of the ISO 787-23 and DMA-CPMA methods of determining powder and aerosol samples

\begin{tabular}{|c|c|c|c|c|c|c|}
\hline Nature & Name & Diameter & $\begin{array}{c}\text { Reference } \\
\text { true density } \\
\left(\mathrm{kg} / \mathrm{m}^{3}\right)\end{array}$ & $\begin{array}{c}\text { OC } \\
\text { content }(\%)\end{array}$ & $\begin{array}{c}\text { Measured } \\
\text { true density } \\
\left(\mathrm{kg} / \mathrm{m}^{3}\right)\end{array}$ & Source \\
\hline $\begin{array}{c}\text { Glass } \\
\text { marbles }\end{array}$ & Glass & - & 2500 & n.r. & $2369+/-39$ & - \\
\hline Alumina & $\mathrm{Al}_{2} \mathrm{O}_{3}$ & - & $3950^{1}$ & n.r. & $3937+/-25$ & ${ }^{1}$ Durmax \\
\hline \multirow{3}{*}{$\begin{array}{l}\text { Black } \\
\text { carbon }\end{array}$} & LB 101 & $95 \mathrm{~nm}^{2}$ & $1770^{3}$ & $\begin{array}{c}0.8 \%{ }^{2} \\
0.8 \%+/-0.1 \% 4\end{array}$ & $1717+/-49$ & $\begin{array}{c}{ }^{2} \text { (Saber et al., 2012) } \\
{ }^{3} \text { manufacturer } \\
{ }^{4} \text { present study }\end{array}$ \\
\hline & Printex 90 & $14 \mathrm{~nm}^{5}$ & $1800^{5}$ & $\begin{array}{c}2.0 \%^{6} \\
1.3 \%+/-0.1 \% 4\end{array}$ & $1791+/-15$ & $\begin{array}{l}{ }^{5} \text { (De Temmerman et } \\
\text { al., 2014) } \\
{ }^{6} \text { (Ferge et al., 2006) }\end{array}$ \\
\hline & Printex 25 & $49 \mathrm{~nm}^{7}$ & $1800^{3}$ & $0.9 \% 3$ & $1878+/-15$ & $\begin{array}{c}{ }^{7} \text { (Pawlyta et al., } \\
\text { 2015) }\end{array}$ \\
\hline $\begin{array}{l}\text { Glassy } \\
\text { carbon }\end{array}$ & Glassy C. & $0.4-12 \mu \mathrm{m}^{8}$ & $1400^{8}$ & - & $1402+/-17$ & ${ }^{8}$ Good-fellow \\
\hline \multicolumn{7}{|c|}{ Samples used for validation of the DMA-CPMA approach } \\
\hline $\begin{array}{c}\text { Spark } \\
\text { discharge } \\
\text { carbonaceous } \\
\text { aggregates }\end{array}$ & GFG1000 & $\begin{array}{c}7^{9}-8.6^{10} \\
\mathrm{~nm}\end{array}$ & $\begin{array}{l}2000^{10} \\
2250^{09}\end{array}$ & $4.0 \% 11$ & $2150^{11}$ & $\begin{array}{l}{ }^{9} \text { (Charvet et al., } \\
\text { 2014) } \\
{ }^{10} \text { (Schnaiter et al., } \\
\text { 2003) }\end{array}$ \\
\hline $\begin{array}{l}\text { Propane } \\
\text { diffusion } \\
\text { flame } \\
\end{array}$ & $\begin{array}{c}\text { CAST } \\
16.2 \% \text { OC }\end{array}$ & $27 \mathrm{~nm}^{11}$ & $1631+/-132 *$ & $16.2 \%$ & $1543^{11}$ & ${ }^{11}$ (Yon et al., 2015) \\
\hline & $\begin{aligned} \text { n.r.: } \\
* \text { refe }\end{aligned}$ & true densi & $\begin{array}{l}\text { urement is not } 1 \\
\text { for CAST samp }\end{array}$ & $\begin{array}{l}\text { evant for glass mai } \\
\text { determined accorc }\end{array}$ & $\begin{array}{l}\text { s and alumin } \\
\text { to ISO } 787-\end{array}$ & \\
\hline
\end{tabular}

As mentioned above, the main disadvantage of the ISO 787-23 method is the need for a significant sample mass (at least $100 \mathrm{mg}$ ). For soot sources such as a gaseous burner (miniCAST) and aircraft engine, the minimum amount of particles needed to apply the ISO 787-23 method is difficult to achieve. Consequently, for these particles, the DMA-CPMA method linked to TEM analysis of primary particle size distribution in terms of diameter, was considered (Park et al., 2004). Further details regarding the feasibility of this approach for determining soot true density could be retrieved in Yon et al. (Yon et al., 2015). Validation of this method has been performed for spark discharge nanoparticle aggregates (GFG1000) and propane diffusion flame soot 
particles (CAST with an OC/TC content of 16.2\%), and their physico-chemical properties are also reported in Table 1. Reference true density was considered from previous studies (Charvet et al., 2014; Schnaiter et al., 2003) for GFG1000 and from direct measurements based on previously validated ISO 787-23 for CAST. A good agreement (within $+/-5 \%$ ) is also reported in Figure 2 for the DMA-CPMA approach, confirming the relevance of this alternative method for measuring soot true density.

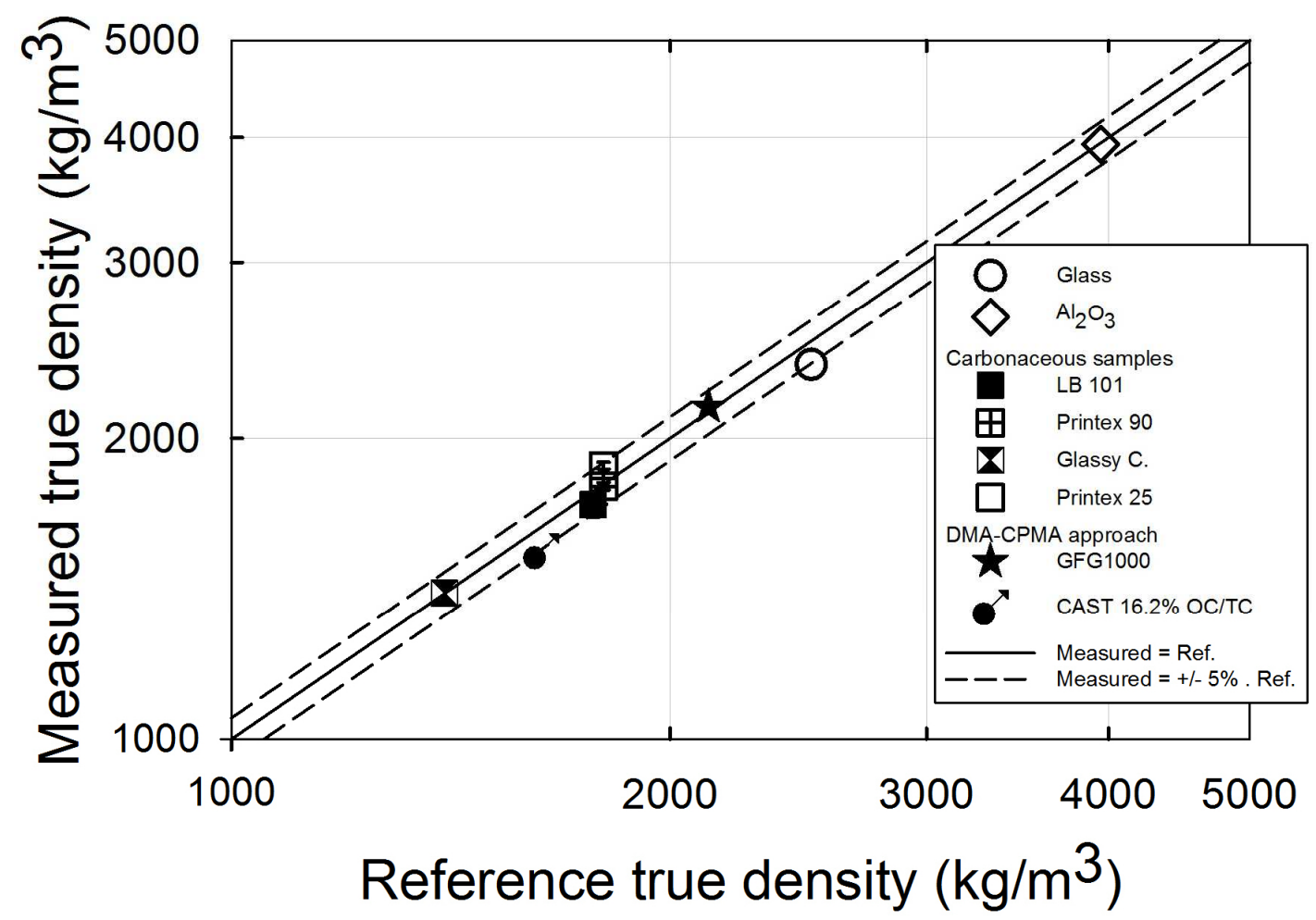

Figure 2: validation of the true density measurement methods ISO 787-23 and DMA-CPMA with reference powders

\section{Experimental results: evidence of the influence of organic carbon content}

The $\chi^{2}$ test confirmed the homogeneity of the reference sample composition. However, several soot samples did not pass the $\chi^{2}$ test (see Annex III), demonstrating, statistically, that the composition of these soot samples was not homogeneous. Nevertheless, final uncertainties were estimated taking into account this dispersion, enabling the associated mean values to be discussed.

The properties of the analyzed samples are summarized in Table 2. Since complex fire conditions were considered in the present work, clarification of the different definitions associated with combustion emitted particles is needed. Following Petzold et al. (2013), in the present study soot will refer to samples mostly consisting of carbon, with small amounts of hydrogen and oxygen and, for the present study, with an OC/TC ratio below $5 \%$. Combustion emitted particles will refer to all other samples, denoting significant amounts of organic content and metals.

Soot true densities obtained by previous authors are also reported in Table 2 for comparison. In addition to true density, OC content is reported, corresponding to the organic to total carbon ratio OC/TC determined, in the present study with a thermo-optical device (Sunset Lab) using the improved protocol (Chow et al., 2007). Soot particles were sampled on pre-baked (at $850^{\circ} \mathrm{C}$ for 1 hour) quartz fiber filters (Pall Tissuquartz 2500 QAT-UP, $47 \mathrm{~mm}$ in diameter) and three punches of $1.5 \mathrm{~cm}^{2}$ each were analyzed for each sample. Sampling flowrates were dependent on experimental conditions (from 1 to $5 \mathrm{~L} / \mathrm{min}$ ). Furthermore, samplings were carried out close to the emission point (in order to be as representative as possible of fresh combustion aerosol without any ageing effect), at temperatures near $100^{\circ} \mathrm{C}$. For this reason, semivolatile vapor adsorption was not considered to be 
significant within our experimental conditions (Turpin \& Huntzicker, 1994). For samples identified from the literature for which OC/TC is not available, OC content is associated with carbon-to-oxygen ratio $\mathrm{C} / \mathrm{O}$ or oxygen content $\mathrm{O}$, determined by elemental analysis.

Within the present work, soot and combustion emitted particles are produced by different means at different scales: analytical test bench based on miniCAST soot generator (Yon et al., 2015), cone calorimeter (Mocho \& Ouf, 2011; Ouf et al., 2015; Ouf et al., 2008), large-scale fires in over-ventilated/open (SATURNE facility) or under-ventilated/confined (DIVA facility) conditions (Ouf et al., 2014) and even during an aircraft engine test (Delhaye et al., 2017). Soot particles are generally pneumatically retrieved from previously clogged High Efficiency Particulate Air Filters installed in the ventilation networks of test benches.

In the case of laboratory gaseous diffusion flames, except for the miniCAST burner (Yon et al., 2015), the results reported in the literature and in the present study are in close agreement. According to values reported for gaseous burners, associated with low levels of organic content (i.e. below 5\%, marked in Table 2 by an "*" and previously defined as soot particles), a mean value of $1834+/-187 \mathrm{~kg} / \mathrm{m}^{3}$ is proposed for particles produced by gaseous fuels (acetylene, propylene, ethylene, methane, propane) and liquid fuels (toluene, n-heptane, diesel).

For other diffusion flames of liquids or polymers (samples marked by ** or no asterisk in Table 2), combustion emitted particles denote higher OC/TC ratios and significantly lower true densities than the previously reported mean value of $1834 \mathrm{~kg} / \mathrm{m}^{3}$. A similar trend is also noticed for the miniCAST and aircraft particles, which also denote a high OC content.

Figure 3 presents the evolution of the true density of the samples considered, reported in Table 2 as a function of the organic carbon content (OC/TC ratio). Since the soluble organic fraction of the OC/TC fraction of the samples considered could be dissolved by ethanol, some of the samples were analysed in terms of OC/TC ratio before and after this centrifugation step. The corresponding variation in the OC/TC ratio was added in Figure 3 as dispersion bars for this property; more details are available in Annex IV. 
Table 2: properties and true density of combustion emitted particle samples

\begin{tabular}{|c|c|c|c|c|c|}
\hline Source & Fuel & OC content & Method & True density $\left(\mathrm{kg} / \mathrm{m}^{3}\right)$ & Reference \\
\hline \multirow{10}{*}{ Diffusion flame } & Acetylene $\left(\mathrm{C}_{2} \mathrm{H}_{2}\right)$ & $\mathrm{C} / \mathrm{O}: 107$ & \multirow{6}{*}{$\begin{array}{l}\text { Helium } \\
\text { pycnometry }\end{array}$} & $1870^{*}$ & \multirow{4}{*}{ (Wu, Krishnan, \& Faeth, 1997) } \\
\hline & Propylene $\left(\mathrm{C}_{3} \mathrm{H}_{6}\right)$ & $\mathrm{C} / \mathrm{O}: 57.6$ & & $1850 *$ & \\
\hline & Ethylene $\left(\mathrm{C}_{2} \mathrm{H}_{4}\right)$ & - & & $1930^{*}$ & \\
\hline & Propane $\left(\mathrm{C}_{3} \mathrm{H}_{8}\right)$ & - & & $1900 *$ & \\
\hline & Acetylene $\left(\mathrm{C}_{2} \mathrm{H}_{2}\right)$ & $2.3 \% \mathrm{O}$ & & $2050 *$ & (Roessler \& Faxvog, 1980) \\
\hline & Acetylene $\left(\mathrm{C}_{2} \mathrm{H}_{2}\right)$ & - & & $1740+/-100 *$ & (Choi et al., 1995) \\
\hline & Toluene $\left(\mathrm{C}_{7} \mathrm{H}_{8}\right)$ & C/O: $7.52+/-0.74$ & \multirow{4}{*}{$\begin{array}{c}\text { Helium } \\
\text { displacement } \\
\text { with BET } \\
\text { apparatus }\end{array}$} & $1800+/-20 *$ & \multirow{4}{*}{ (Mullins \& Williams, 1987) } \\
\hline & Propane $\left(\mathrm{C}_{3} \mathrm{H}_{8}\right)$ & $\mathrm{C} / \mathrm{O}: 9.43+/-0.03$ & & $1770+/-20 *$ & \\
\hline & n-Heptane $\left(\mathrm{C}_{7} \mathrm{H}_{16}\right)$ & C/O: $8.35+/-0.73$ & & $1780+/-20 *$ & \\
\hline & Methane $\left(\mathrm{CH}_{4}\right)$ & C/O: $5.66+/-0.30$ & & $1830+/-20 *$ & \\
\hline \multirow{3}{*}{$\begin{array}{l}\text { Automotive } \\
\text { engine }\end{array}$} & \multirow{2}{*}{ Diesel fuel } & 30 & \multirow{3}{*}{ DMA-APM } & 1270 for soot size $50 \mathrm{~nm}^{* *}$ & \multirow{3}{*}{$\begin{array}{c}\text { (Park et al., 2004) } \\
\text { (Sakurai et al., 2003) }\end{array}$} \\
\hline & & 10 & & 1780 for soot size $220 \mathrm{~nm}$ & \\
\hline & Diesel fuel & - & & $1770+/-70$ for soot at $300^{\circ} \mathrm{C}^{*}$ & \\
\hline \multirow{7}{*}{$\begin{array}{l}\text { Diffusion } \\
\text { Flame } \\
\text { (cone } \\
\text { calorimeter) }\end{array}$} & Acetylene $\left(\mathrm{C}_{2} \mathrm{H}_{2}\right)(\mathrm{BANCO})$ & 5 & \multirow{7}{*}{$\begin{array}{c}\text { Volume } \\
\text { displacement } \\
\text { method } \\
\text { ISO 787-23 }\end{array}$} & $1719+/-30^{*}$ & \multirow{7}{*}{ Present study } \\
\hline & Toluene $\left(\mathrm{C}_{7} \mathrm{H}_{8}\right) 450(\mathrm{BANCO})$ & 16.3 & & $1515+/-191$ & \\
\hline & Toluene $\left(\mathrm{C}_{7} \mathrm{H}_{8}\right) 100(\mathrm{BANCO})$ & 25.0 & & $1483+/-100 * *$ & \\
\hline & PMMA $^{1}\left(\mathrm{C}_{5} \mathrm{H}_{8} \mathrm{O}_{2}\right) 450(\mathrm{BANCO})$ & 10.1 & & $1648+/-78$ & \\
\hline & $\mathrm{PMMA}^{1}\left(\mathrm{C}_{5} \mathrm{H}_{8} \mathrm{O} 2\right) 100(\mathrm{BANCO})$ & 15.3 & & $1492+/-12$ & \\
\hline & $2 / 3 \mathrm{PMMA}^{1}+1 / 3 \mathrm{PVC}^{1}(\mathrm{BANCO})$ & $14.8+/-2.3$ & & $1315+/-82$ & \\
\hline & $\mathrm{TBP}^{2} / \mathrm{TPH}^{2}(\mathrm{PARIS})$ & $15.0+/-1.4$ & & $1534+/-78^{\dagger}$ & \\
\hline \multirow{4}{*}{$\begin{array}{c}\text { miniCAST } \\
\text { diffusion flame }\end{array}$} & \multirow{4}{*}{$\begin{array}{l}\text { Propane with different } \\
\text { fuel to air ratios }\end{array}$} & 16.2 & \multirow{5}{*}{ DMA-CPMA } & 1543 & \multirow{4}{*}{ (Yon et al., 2015) } \\
\hline & & 58.3 & & $1234 * *$ & \\
\hline & & 87 & & $1321 * *$ & \\
\hline & & 22 & & $1227 * *$ & \\
\hline Aircraft engine & Kerozene & $25.8+/-1.5$ & & $1174 * *$ & Present study \\
\hline \multirow{7}{*}{ Real scale fire } & Electrical elements (BANCO) & $37.6+/-1.7$ & \multirow{7}{*}{$\begin{array}{c}\text { Volume } \\
\text { displacement } \\
\text { method } \\
\text { ISO 787-23 }\end{array}$} & $1762+/-6^{\dagger \dagger}$ & \multirow{7}{*}{ Present study } \\
\hline & Electrical cabinet (DIVA) & $37.6+/-1.7$ & & $1672+/-29^{\dagger \dagger}$ & \\
\hline & Electrical cables (CFS) & $55.3+/-2.8^{\dagger \dagger}$ & & $2000+/-68^{\dagger \dagger}$ & \\
\hline & Electrical cable with PVC (CORE) & $8.4+/-1.0^{\dagger \dagger}$ & & $1768+/-39^{\dagger \dagger}$ & \\
\hline & Hydraulic oil (FES) & $10.3+/-0.4$ & & $1665+/-164$ & \\
\hline & Gloves box (SATURNE) & $6.2+/-0.6$ & & $1749+/-82$ & \\
\hline & Gloves box (DIVA) & $48.1+/-3.4^{\dagger \dagger}$ & & $2069+/-35^{\dagger \dagger}$ & \\
\hline
\end{tabular}




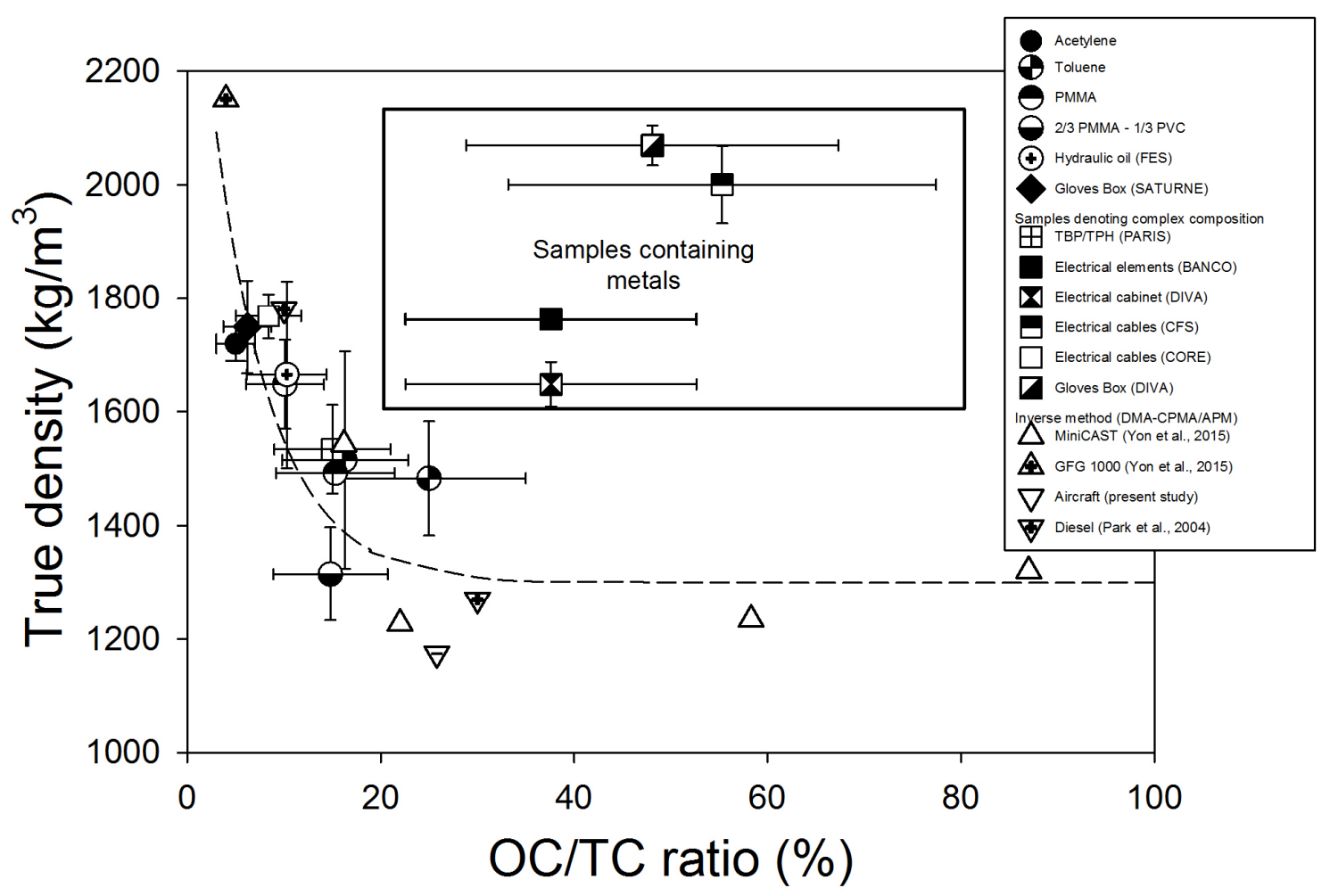

Figure 3: evolution of combustion emitted particle true density as a function of OC/TC ratio (dashed line is a guide to the eye)

High true density values are observed for several samples (electrical elements, electrical cabinet, electrical cables and glove box soot produced within the DIVA facility), even with a significant OC content. This discrepancy with other samples is mainly due to the significant metal content (iron, copper, etc.) reported for these samples, which tends to significantly enhance the true density of the mixing of carbonaceous particles with metallic particles.

For low OC contents (below 5\%), the true density could be considered constant with a corresponding mean value of $1834+/-187 \mathrm{~kg} / \mathrm{m}^{3}$ as previously proposed (see samples marked by an “*” in Table 2). For OC contents above $20 \%$ (miniCAST and aircraft soot), the true density is almost constant and close to a mean value (calculated using the samples marked "**” in Table 2) of $1285+/-217 \mathrm{~kg} / \mathrm{m}^{3}$. By assuming that OC is mainly composed by Polycyclic Aromatic Hydrocarbons (PAH), then higher OC content could be associated with heavier PAHs formed by the miniCAST burner (Mueller et al., 2015), the present asymptotic density value is in close agreement with the density of several PAHs reported in the literature (i.e. from $980 \mathrm{~kg} / \mathrm{m}^{3}$ for phenanthrene to $1351 \mathrm{~kg} / \mathrm{m}^{3}$ for benzo[ $\left.\alpha\right]$ pyrene, ATSDR, 1995).

In between, a straight decrease of true inherent density is observed as OC mass fraction increases. As reported by several authors (Park et al., 2004; Sakurai et al., 2003), the density of diesel particles is strongly affected by the organic content and tends to decrease from the true density of the elemental carbon (EC) (close to $2000 \mathrm{~kg} / \mathrm{m}^{3}$, CRC, 2002) to the density of the organic matter condensed on the diesel soot particles (OC). Those authors also proposed, based on a mixing law approach, defining the inherent true density $\rho_{\text {inherent }}$ as a function of the respective density of these two carbonaceous fractions:

$$
\rho_{\text {inherent }}=\frac{M_{\mathrm{OC}}+M_{\mathrm{EC}}}{v_{\mathrm{OC}}+V_{\mathrm{EC}}}=\frac{M_{\mathrm{OC}}+M_{\mathrm{EC}}}{\frac{M_{\mathrm{OC}}}{\rho_{\mathrm{OC}}}+\frac{M_{\mathrm{EC}}}{\rho_{\mathrm{EC}}}}=\frac{x+(1-\mathrm{x})}{\frac{x}{\rho_{\mathrm{OC}}}+\frac{1-\mathrm{x}}{\rho_{\mathrm{EC}}}},
$$

where $\mathrm{M}_{\mathrm{OC}}, \mathrm{V}_{\mathrm{OC}}$ and $\rho_{\mathrm{OC}}$ are, respectively, the mass, the volume and the density of organic condensed carbon, $\mathrm{M}_{\mathrm{EC}}, \mathrm{V}_{\mathrm{EC}}$ and $\rho_{\mathrm{EC}}$ are respectively the mass, the volume and the density of elemental carbon, and $\mathrm{x}$ is the mass 
fraction of organic carbon $\left(x=\frac{M_{O C}}{M_{O C}+M_{E C}}\right)$ as determined by thermo-optical analysis. However, this type of equation fails to reproduce the observed trend shown in Figure 3 since the composition of OC content could evolve as OC/TC ratio increases. By considering the measured inherent density and $\rho_{\mathrm{EC}}=1834 \mathrm{~kg} / \mathrm{m}^{3}$ in the mixing law (eq. 10), the density of the organic phase ( $\rho_{\mathrm{OC}}$ ) could be calculated (eq. 11). For samples containing metals, this density will also take into account the density of the metallic fraction of particles.

$$
\rho_{\mathrm{OC}}=x\left(\frac{1}{\frac{1}{\rho_{\text {measured }}-\frac{(1-\mathrm{x})}{\rho_{\mathrm{EC}}}}}\right)
$$

The trend obtained for the density of the OC fraction as a function of the OC/TC ratio is presented in Figure 4.

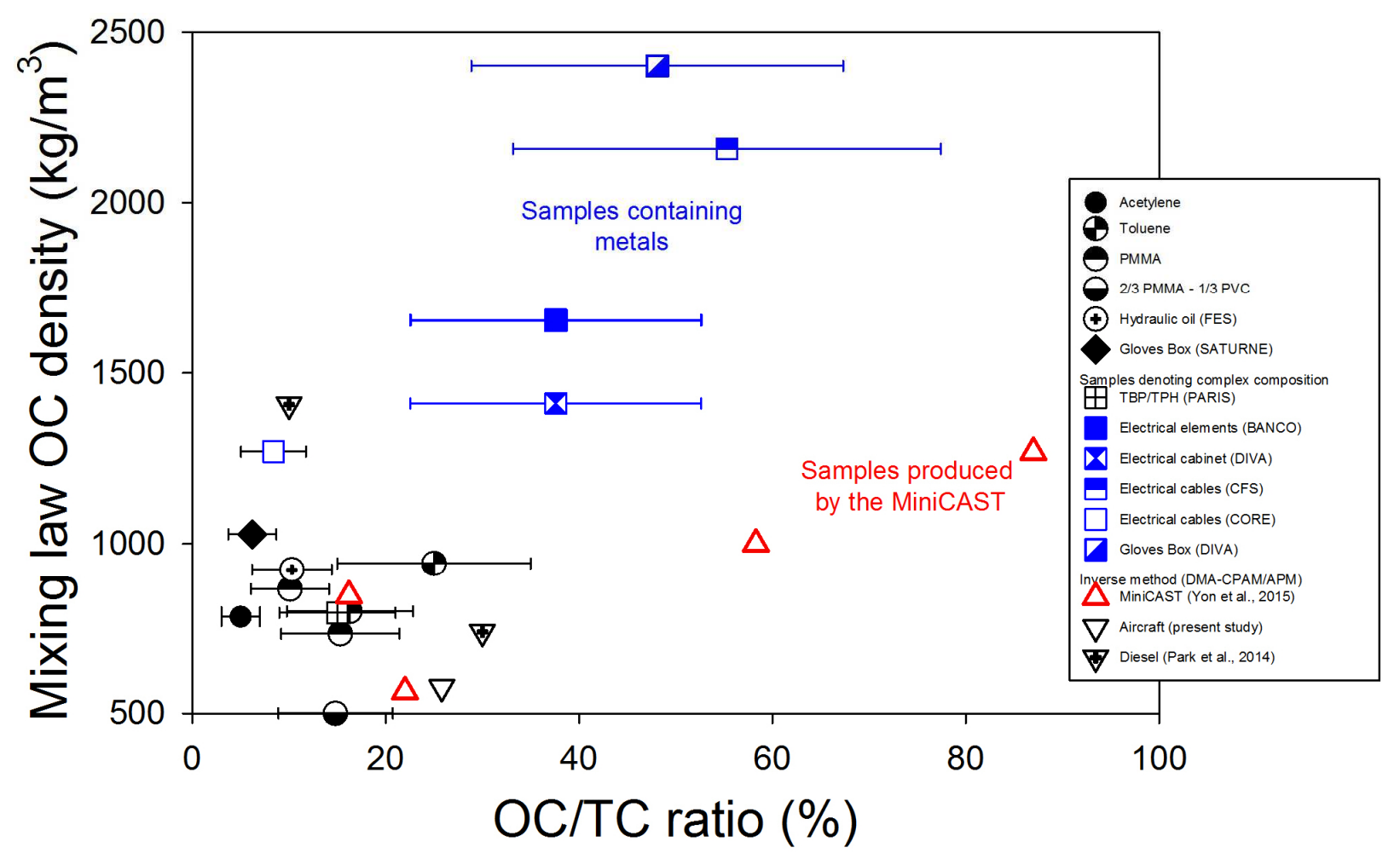

Figure 4: evolution, as a function of OC/TC ratio, of the density of the OC fraction of the sample, determined by assuming equation 10 as a mixing law for describing the inherent density of combustion emitted particles

High density values computed for particles emitted during electrical cable/element fires (BANCO, DIVA, CFS) and in ventilated glove box (DIVA) fires, confirm the significant presence of metallic compounds in addition to a high OC fraction (expected to have a density significantly lower than $\rho_{\mathrm{EC}}$ ). For such samples, a mixing law based on two phases (EC and OC) is not relevant and should be improved by taking into account a metalcontaining phase fixed on the particle surface.

For samples with lower OC content (OC < 20\%) no specific trend can be identified. This could be explained by the variety of particle production conditions (fuels, ventilation, etc.), producing different types of organic component associated with different densities (from 500 to $1400 \mathrm{~kg} / \mathrm{m}^{3}$ ).

Such discrepancies are not noticeable in the case of the miniCAST soot, where the density of the OC fraction appears to increase with the OC/TC ratio. This evolution agrees with recent findings reported for miniCAST soot particles (Mueller et al., 2015). The authors then demonstrated that flames denoting a higher fuel-to-air equivalence ratio tend to produce soot with a higher OC/TC content associated with heavier PAHs denoting higher density. By assuming the elemental carbon soot density, the present approach means that it is then possible to reasonably compute the density of the organic fraction of the soot samples. Such findings are also in 
agreement with a recent review by Olfert \& Rogak (2019), which aims to propose "universal relations between soot effective density and primary combustion sources". It should be borne in mind that such an approach, to be fulfilled for large range of combustion sources, requires soot density to be uniform (as reported in the present study) and, consequently, OC density to be approximately the same for different sources. The present experimental method of determination of $\mathrm{OC}$ density, linked to effective density measurements, could potentially pave the way for the extension of these "universal relations" to other combustion emitted particles.

\section{Experimental results: temperature effect on the true density of combustion emitted particles}

Considering the previously reported strong influence of potentially volatile OC content on the true density of combustion emitted particles, it could be suspected that this property must be strongly affected by temperature through OC desorption from the surface of the particles. Such an assumption is essential for fire applications since the temperature within a ventilated fire room could range from ambient temperature up to $200-300^{\circ} \mathrm{C}$. With the aim of confirming the significant influence of the carbonaceous organic content on the true density of samples and the effect of temperature on the same property, density measurements were carried out in accordance with ISO 787-23, on four samples at ambient temperatures and after 24 hours of heat treatment in a furnace at $120^{\circ} \mathrm{C}$ and $240^{\circ} \mathrm{C}$ respectively. Figure 5 presents the true density of the samples as a function of the post-treatment temperature. For all samples treated under these conditions, the true density does not significantly evolve and remains close to the values determined at ambient temperature. Such a conclusion demonstrates that the organic compounds in the samples considered are stable up to $240^{\circ} \mathrm{C}$, a temperature representative of those encountered during a fire in a confined and poorly ventilated facility. This finding is in good agreement with Ferraro et al. (2016) who reported, based on the TGA analysis of soot particles, that the decomposition of such particles starts at $300^{\circ} \mathrm{C}$. Supporting this assumption, Figure A2 (Annex V) presents the evolution of the fraction of OC analyzed at the different temperature steps of the EC/OC analyzer $\left(140,280,480\right.$ and $580^{\circ} \mathrm{C}$ based on the IMPROVE_A protocol). For all samples, the fraction of OC denoting the highest volatility (desorbed below $280^{\circ} \mathrm{C}$ ) represents less than $30 \%$ of the entire $\mathrm{OC}$ content, confirming the limited effect of temperature on the true densities of samples even after 24 hours at $240^{\circ} \mathrm{C}$, shown in Figure 5. These organic materials can be strongly bonded to the particle surface by chemisorption and can be transported from their point of emission into ventilation ducts, eventually being found on High Efficiency Particulate Air filters as mentioned by Mocho \& Ouf (2011).

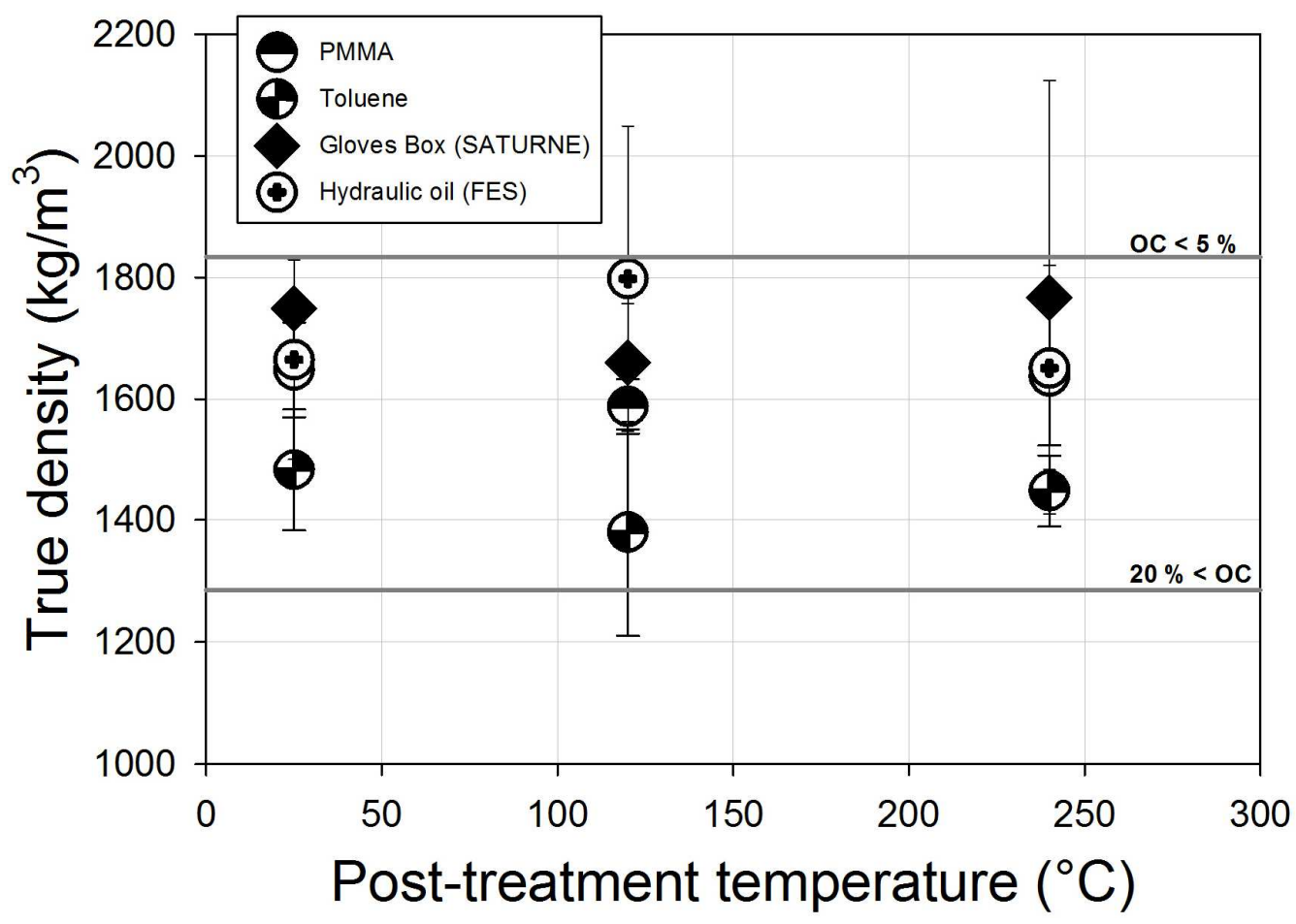

Figure 5: sample true density as a function of post-treatment temperature 


\section{$\underline{\text { Conclusions }}$}

The measurement of powder true density using the ISO 787-23 method was validated on carbonaceous particles with micronic and nanometric size distribution. Agreement within $+/-5 \%$, explained by the experimental uncertainty associated with the measurement protocol, was reported for reference samples, confirming that this method, initially used specifically for micronic powders, is also suitable for measuring the true density of nanostructured samples such as soot particles. The agreement of the true density of the reference samples with DMA-CPMA methods is also found to be good.

True densities were determined for 13 soot samples using the ISO 787-23 method and were compared to values previously reported in the literature or indirectly obtained by DMA-CPMA analysis. Mean values of $1834+/-$ $187 \mathrm{~kg} / \mathrm{m}^{3}$ and $1285+/-217 \mathrm{~kg} / \mathrm{m}^{3}$ were proposed for soot, respectively denoting low (<5\%) and high $(>20 \%)$ OC contents. For intermediate OC contents, a mixing law was proposed for prediction of soot density. Larger true densities were determined for soot produced in complex fires, which consequently include metals in their composition.

\section{Acknowledgements}

The authors would like to thank Guillaume Basso, Mickael Coutin, Vincent Cozar, Hugues Pretrel, Serge Pons and Pascal Zavaleta from the "Laboratoire d'Expérimentation des Feux" in Cadarache for providing soot samples emitted during large-scale fire experiments. This work was partially done within the framework of the LIMA joint research program (The Interactions Media-Aerosol Laboratory) between the Institut de Radioprotection et de Sûreté Nucléaire (IRSN) and the Reactions and Chemical Engineering Laboratory (LRGP) of the French National Centre for Scientific Research (CNRS).

\section{References:}

(ATSDR), A. for T. S. and D. R. (1995). Toxicological profile for polycyclic aromatic hydrocarbones.

Bond, T. C., Doherty, S. J., Fahey, D. W., Forster, P. M., Berntsen, T., DeAngelo, B. J., .. Zender, C. S. (2013). Bounding the role of black carbon in the climate system: A scientific assessment. Journal of Geophysical Research: Atmospheres, 118(11), 5380-5552. http://doi.org/10.1002/jgrd.50171

Bourrous, S., Ribeyre, Q., Lintis, L., Yon, J., Bau, S., Thomas, D., ... Ouf, F. F.-X. (2018). A semi-automatic analysis tool for the determination of primary particle size, overlap coefficient and specific surface area of nanoparticles aggregates. Journal of Aerosol Science, 126(February), 122-132. http://doi.org/10.1017/S0950268817001236.

Charvet, A., Bau, S., Paez Coy, N. E., Bémer, D., \& Thomas, D. (2014). Characterizing the effective density and primary particle diameter of airborne nanoparticles produced by spark discharge using mobility and mass measurements (tandem DMA/APM). Journal of Nanoparticle Research, 16(5), 2418. http://doi.org/10.1007/s11051-014-2418-y

Choi, M. Y., Mulholland, G. W., Hamins, A., \& Kashiwagi, T. (1995). Comparisons of the soot volume fraction using gravimetric and light extinction techniques. Combustion and Flame, 102(1-2), 161-169. http://doi.org/10.1016/0010-2180(94)00282-W

Chow, J. C., Watson, J. G., Chen, L. W. A., Chang, M. C. O., Robinson, N. F., Trimble, D., \& Kohl, S. (2007). The IMPROVE_A temperature protocol for thermal/optical carbon analysis: maintaining consistency with a long-term database. Journal of the Air \& Waste Management Association (1995), 57, 1014-1023. http://doi.org/10.3155/1047-3289.57.9.1014

CRC. (2002). CRC Handbook of Chemistry and Physics. CRC Press, Boca Raton, FL.

Dean, J. A. (1990). Lange's Handbook of Chemistry 10th edition (10th ed.). http://doi.org/10.1016/S0016- 
0032(40)90947-4

De Temmerman, P. J., Verleysen, E., Lammertyn, J., \& Mast, J. (2014). Semi-automatic size measurement of primary particles in aggregated nanomaterials by transmission electron microscopy. Powder Technology, 261, 191-200. http://doi.org/10.1016/j.powtec.2014.04.040

Delhaye, D., Ouf, F.-X., Ferry, D., Ortega, I. K., Penanhoat, O., Peillon, S., ... Gaffie, D. (2017). The MERMOSE project: Characterization of particulate matter emissions of a commercial aircraft engine. Journal of Aerosol Science, 105. http://doi.org/10.1016/j.jaerosci.2016.11.018

Dobbins, R. A., Mulholland, G. W., \& Bryner, N. P. (1994). Comparison of a fractal smoke optics model with light extinction measurements. Atmospheric Environment, 28(5), 889-897. http://doi.org/10.1016/13522310(94)90247-X

Ehara, K., Hagwood, C., \& Coakley, K. J. (1996). Novel method to classify aerosol particles according to their mass-to-charge ratio - Aerosol particle mass analyser. Journal of Aerosol Science, 27(2), 217-234. http://doi.org/10.1016/0021-8502(95)00562-5

Ferge, T., Karg, E., Schröppel, A., Coffee, K. R., Tobias, H. J., Frank, M., ... Zimmermann, R. (2006). Fast determination of the relative elemental and organic carbon content of aerosol samples by on-line singleparticle aerosol time-of-flight mass spectrometry. Environmental Science and Technology, 40(10), 33273335. http://doi.org/10.1021/es050799k

Ferraro, G., Fratini, E., Rausa, R., Fiaschi, P., \& Baglioni, P. (2016). Multiscale Characterization of Some Commercial Carbon Blacks and Diesel Engine Soot. Energy and Fuels, 30(11), 9859-9866. http://doi.org/10.1021/acs.energyfuels.6b01740

Kennedy, I. M. (1997). Models of soot formation and oxidation. Progress in Energy and Combustion Science, 23(2), 95-132. http://doi.org/10.1016/S0360-1285(97)00007-5

McMurry, P. H., Wang, X., Park, K., \& Ehara, K. (2002). The relationship between mass and mobility for atmospheric particles: A new technique for measuring particle density. Aerosol Science and Technology, 36(2), 227-238. http://doi.org/10.1080/027868202753504083

Michelsen, H. A., Liu, F., Kock, B. F., Bladh, H., Boiarciuc, A., Charwath, M., ... Suntz, R. (2007). Modeling laser-induced incandescence of soot: a summary and comparison of LII models. Applied Physics B Lasers and Optics, 87(3), 503-521. http://doi.org/10.1007/s00340-007-2619-5

Mocho, V. M., \& Ouf, F. X. (2011). Clogging of industrial pleated high efficiency particulate air (HEPA) filters in the event of fire. Nuclear Engineering and Design, 241(5), 1785-1794. http://doi.org/10.1016/j.nucengdes.2011.01.036

Mueller, L., Jakobi, G., Orasche, J., Karg, E., Sklorz, M., Abbaszade, G., ... Zimmermann, R. (2015). Online determination of polycyclic aromatic hydrocarbon formation from a flame soot generator. Analytical of Bioanalytical Chemistry, 407(20), 5911-5922.

Mullins, J., \& Williams, A. (1987). The optical properties of soot: a comparison between experimental and theoretical values. Fuel, 66, 277-280. http://doi.org/10.1111/j.1365-263X.1994.tb00128.x

Neuilly, M., \& CETAMA. (1998). Modélisation et estimation des erreurs de mesure. (Lavoisier, Ed.).

Olfert, J., \& Rogak, S. (2019). Universal relations between soot effective density and primary particle size for common combustion sources. Aerosol Science and Technology, O(0), 1-9. http://doi.org/10.1080/02786826.2019.1577949

Olfert, J. S., \& Collings, N. (2005). New method for particle mass classification-the Couette centrifugal particle mass analyzer. Journal of Aerosol Science, 36(11), 1338-1352. http://doi.org/10.1016/j.jaerosci.2005.03.006

Ouf, F.-X., Mocho, V.-M., Pontreau, S., Wang, Z., Ferry, D., \& Yon, J. (2014). Clogging of industrial High Efficiency Particulate Air (HEPA) filters in case of fire: From analytical to large-scale experiments. Aerosol Science and Technology, 48(9). http://doi.org/10.1080/02786826.2014.947022 
Ouf, F.-X., Mocho, V.-M., Pontreau, S., Wang, Z., Ferry, D., \& Yon, J. (2015). Physicochemical properties of aerosol released in the case of a fire involving materials used in the nuclear industry. Journal of Hazardous Materials, 283, 340-349. http://doi.org/10.1016/j.jhazmat.2014.09.043

Ouf, F.-X., Vendel, J., Coppalle, A., Weill, M., \& Yon, J. (2008). Characterization of Soot Particles in the Plumes of Over-Ventilated Diffusion Flames. Combustion Science and Technology, 180(4), 674-698.

Park, K., Kittelson, D. B., \& McMurry, P. H. (2004). Structural properties of diesel exhaust particles measured by Transmission Electron Microscopy (TEM): Relationships to particle mass and mobility. Aerosol Science and Technology, 38(9), 881-889. http://doi.org/10.1080/027868290505189

Pawlyta, M., Rouzaud, J.-N., \& Duber, S. (2015). Raman microspectroscopy characterization of carbon blacks: Spectral analysis and structural information. Carbon, 84, 479-490. http://doi.org/10.1016/j.carbon.2014.12.030

Petzold, a., Ogren, J. a., Fiebig, M., Laj, P., Li, S. M., Baltensperger, U., ... Zhang, X. Y. (2013). Recommendations for reporting black carbon measurements. Atmospheric Chemistry and Physics, 13(16), 8365-8379. http://doi.org/10.5194/acp-13-8365-2013

Roessler, D. M., \& Faxvog, F. R. (1980). Optical properties of agglomerated acetylene smoke particles at 05145$\mu \mathrm{m}$ and 106- $\mu \mathrm{m}$ wavelengths. Journal of the Optical Society of America, 70(2), 230. http://doi.org/10.1364/JOSA.70.000230

Saber, A. T., Jensen, K. A., Jacobsen, N. R., Birkedal, R., Mikkelsen, L., Møller, P., ... Vogel, U. (2012). Inflammatory and genotoxic effects of nanoparticles designed for inclusion in paints and lacquers. Nanotoxicology, 6(5), 453-71. http://doi.org/10.3109/17435390.2011.587900

Sakurai, H., Park, K., McMurry, P. H., Zarling, D. D., Kittelson, D. B., \& Ziemann, P. J. (2003). Size-Dependent Mixing Characteristics of Volatile and Nonvolatile Components in Diesel Exhaust Aerosols. Environmental Science and Technology, 37(24), 5487-5495. http://doi.org/10.1021/es034362t

Schnaiter, M., Horvath, H., Möhler, O., Naumann, K.-H., Saathoff, H., \& Schöck, O. W. (2003). UV-VIS-NIR spectral optical properties of soot and soot-containing aerosols. Journal of Aerosol Science, 34(10), 14211444. http://doi.org/10.1016/S0021-8502(03)00361-6

Thomas, D., Ouf, F. X., Gensdarmes, F., Bourrous, S., \& Bouilloux, L. (2014). Pressure drop model for nanostructured deposits. Separation and Purification Technology, 138, 144-152. http://doi.org/10.1016/j.seppur.2014.09.032

Turpin, B. J., \& Huntzicker, J. J. (1994). Investigation of Organic Aerosol Sampling in the Los Angeles Basin. Atmospheric Environment, 28(19), 3061-3071.

Wu, J.-S., Krishnan, S. S., \& Faeth, G. M. (1997). Refractive Indices at Visible Wavelengths of Soot Emitted From Buoyant Turbulent Diffusion Flames. Journal of Heat Transfer, 119(2), 230. http://doi.org/10.1115/1.2824213

Yon, J., Bescond, A., \& Ouf, F.-X. (2015). A simple semi-empirical model for effective density measurements of fractal aggregates. Journal of Aerosol Science, 87, 28-37. http://doi.org/10.1016/j.jaerosci.2015.05.003 
$\underline{\text { Annex I: Uncertainty analysis }}$

The uncertainty propagation law can be used to compute the relative uncertainty associated with the determined sample density value $\left(\frac{\mathrm{u}\left(\rho_{\text {sample }}\right)}{\rho_{\text {sample }}}\right)$ :

$$
\left[\frac{\mathrm{u}\left(\rho_{\text {sample }}\right)}{\rho_{\text {sample }}}\right]^{2}=\left[\frac{\mathrm{u}\left(\rho_{\text {eth }}\right)}{\rho_{\text {eth }}}\right]^{2}+\left[\frac{\mathrm{u}\left(1-\frac{\left(\mathrm{m}_{3}-\mathrm{m}_{1}\right)}{\left(\mathrm{m}_{2}-\mathrm{m}_{0}\right)}\right)}{1-\frac{\left(\mathrm{m}_{3}-\mathrm{m}_{1}\right)}{\left(\mathrm{m}_{2}-\mathrm{m}_{0}\right)}}\right]^{2}=\left[\frac{\mathrm{u}\left(\rho_{\mathrm{eth}}\right)}{\rho_{\text {eth }}}\right]^{2}+\left[\frac{\mathrm{u}\left(1-\frac{\left(\mathrm{m}_{3}-\mathrm{m}_{1}\right)}{\left(\mathrm{m}_{2}-\mathrm{m}_{0}\right)}\right)}{\frac{\rho_{\text {sample }}}{\rho_{\text {eth }}}}\right]^{2}
$$

Assuming that the sample and the liquid displacement are independent:

$$
\begin{aligned}
& {\left[\frac{\mathrm{u}\left(\rho_{\text {sample }}\right)}{\rho_{\text {sample }}}\right]^{2}=\left[\frac{\mathrm{u}\left(\rho_{\mathrm{eth}}\right)}{\rho_{\text {eth }}}\right]^{2}+\frac{1}{\left[\frac{\rho_{\text {sample }}}{\rho_{\text {eth }}}\right]^{2}} \cdot\left[u(1)^{2}+u\left(\frac{\left(\mathrm{m}_{3}-\mathrm{m}_{1}\right)}{\left(\mathrm{m}_{2}-\mathrm{m}_{0}\right)}\right)^{2}\right],} \\
& {\left[\frac{\mathrm{u}\left(\rho_{\text {sample }}\right)}{\rho_{\text {sample }}}\right]^{2}=\left[\frac{\mathrm{u}\left(\rho_{\mathrm{eth}}\right)}{\rho_{\text {eth }}}\right]^{2}+\frac{1}{\left[\frac{\rho_{\text {sample }}}{\rho_{\text {eth }}}\right]^{2}} \cdot u\left(\frac{\left(\mathrm{m}_{3}-\mathrm{m}_{1}\right)}{\left(\mathrm{m}_{2}-\mathrm{m}_{0}\right)}\right)^{2}} \\
& =\left[\frac{\mathrm{u}\left(\rho_{\mathrm{eth}}\right)}{\rho_{\text {eth }}}\right]^{2}+\frac{\left(\frac{\left(\mathrm{m}_{3}-\mathrm{m}_{1}\right)}{\left(\mathrm{m}_{2}-\mathrm{m}_{0}\right)}\right)^{2}}{\left[\frac{\rho_{\text {sample }}}{\rho_{\text {eth }}}\right]^{2}} \cdot \frac{u\left(\frac{\left(\mathrm{m}_{3}-\mathrm{m}_{1}\right)}{\left(\mathrm{m}_{2}-\mathrm{m}_{0}\right)}\right)^{2}}{\left(\frac{\left(\mathrm{m}_{3}-\mathrm{m}_{1}\right)}{\left(\mathrm{m}_{2}-\mathrm{m}_{0}\right)}\right)^{2}} \\
& =\left[\frac{\mathrm{u}\left(\rho_{\mathrm{eth}}\right)}{\rho_{\mathrm{eth}}}\right]^{2}+\frac{\left(\frac{\left(\mathrm{m}_{3}-\mathrm{m}_{1}\right)}{\left(\mathrm{m}_{2}-\mathrm{m}_{0}\right)}\right)^{2}}{\left[\frac{\rho_{\text {sample }}}{\rho_{\text {eth }}}\right]^{2}} \cdot\left[\frac{u\left(\mathrm{~m}_{3}-\mathrm{m}_{1}\right)^{2}}{\left(\mathrm{~m}_{3}-\mathrm{m}_{1}\right)^{2}}+\frac{u\left(\mathrm{~m}_{2}-\mathrm{m}_{0}\right)^{2}}{\left(\mathrm{~m}_{2}-\mathrm{m}_{0}\right)^{2}}\right] \\
& =\left[\frac{\mathrm{u}\left(\rho_{\mathrm{eth}}\right)}{\rho_{\mathrm{eth}}}\right]^{2}+\frac{\left(\frac{\left(\mathrm{m}_{3}-\mathrm{m}_{1}\right)}{\left(\mathrm{m}_{2}-\mathrm{m}_{0}\right)}\right)^{2}}{\left[\frac{\rho_{\text {sample }}}{\rho_{\text {eth }}}\right]^{2}} \cdot\left[\frac{u\left(\mathrm{~m}_{3}\right)^{2}}{\left(\mathrm{~m}_{3}-\mathrm{m}_{1}\right)^{2}}+\frac{u\left(\mathrm{~m}_{1}\right)^{2}}{\left(\mathrm{~m}_{3}-\mathrm{m}_{1}\right)^{2}}+\frac{u\left(\mathrm{~m}_{2}\right)^{2}}{\left(\mathrm{~m}_{2}-\mathrm{m}_{0}\right)^{2}}+\frac{u\left(\mathrm{~m}_{0}\right)^{2}}{\left(\mathrm{~m}_{2}-\mathrm{m}_{0}\right)^{2}}\right] . \\
& \mathrm{u}\left(\rho_{\text {sample }}\right)^{2}=\left[\frac{\rho_{\text {sample }} \cdot \mathrm{u}\left(\rho_{\text {eth }}\right)}{\rho_{\text {eth }}}\right]^{2}+\left(\rho_{\text {eth }} \cdot \frac{\left(\mathrm{m}_{3}-\mathrm{m}_{1}\right)}{\left(\mathrm{m}_{2}-\mathrm{m}_{0}\right)}\right)^{2} \cdot\left[\frac{u\left(\mathrm{~m}_{3}\right)^{2}}{\left(\mathrm{~m}_{3}-\mathrm{m}_{1}\right)^{2}}+\frac{u\left(\mathrm{~m}_{1}\right)^{2}}{\left(\mathrm{~m}_{3}-\mathrm{m}_{1}\right)^{2}}+\frac{u\left(\mathrm{~m}_{2}\right)^{2}}{\left(\mathrm{~m}_{2}-\mathrm{m}_{0}\right)^{2}}+\frac{u\left(\mathrm{~m}_{0}\right)^{2}}{\left(\mathrm{~m}_{2}-\mathrm{m}_{0}\right)^{2}}\right] \\
& \mathrm{u}\left(\rho_{\text {sample }}\right)=\left[\left(\frac{\rho_{\text {sample }} \cdot \mathrm{u}\left(\rho_{\mathrm{eth}}\right)}{\rho_{\text {eth }}}\right)^{2}+\left(\rho_{\mathrm{eth}} \cdot \frac{\left(\mathrm{m}_{3}-\mathrm{m}_{1}\right)}{\left(\mathrm{m}_{2}-\mathrm{m}_{0}\right)}\right)^{2} \cdot\left(\frac{u\left(\mathrm{~m}_{3}\right)^{2}}{\left(\mathrm{~m}_{3}-\mathrm{m}_{1}\right)^{2}}+\frac{u\left(\mathrm{~m}_{1}\right)^{2}}{\left(\mathrm{~m}_{3}-\mathrm{m}_{1}\right)^{2}}+\frac{u\left(\mathrm{~m}_{2}\right)^{2}}{\left(\mathrm{~m}_{2}-\mathrm{m}_{0}\right)^{2}}+\frac{u\left(\mathrm{~m}_{0}\right)^{2}}{\left(\mathrm{~m}_{2}-\mathrm{m}_{0}\right)^{2}}\right)\right]^{\frac{1}{2}} .
\end{aligned}
$$


The relative uncertainty associated with the ethanol density $\left(\frac{\mathrm{u}\left(\rho_{\mathrm{eth}}\right)}{\rho_{\mathrm{eth}}}\right)$ is defined by:

$$
\left[\frac{\mathrm{u}\left(\rho_{\mathrm{eth}}\right)}{\rho_{\mathrm{eth}}}\right]^{2}=\left[\frac{\mathrm{u}\left(\rho_{0}\right)}{\rho_{0}}\right]^{2}+\left[\frac{\mathrm{u}(273.15+20)}{(273.15+20)}\right]^{2}+\left[\frac{\mathrm{u}(\mathrm{T}+273.15)}{(\mathrm{T}+273.15)}\right]^{2} \approx\left[\frac{\mathrm{u}(\mathrm{T}+273.15)}{(\mathrm{T}+273.15)}\right]^{2}
$$

where: $\mathrm{u}(\mathrm{T})$, is the uncertainty associated with the temperature measured under experimental conditions. In the present study, this uncertainty was considered to be $1^{\circ} \mathrm{C}$ while the ethanol reference density $\rho_{0}$ at $273.15 \mathrm{~K}$ was assumed to be perfectly well-known (with negligible uncertainty).

The compound uncertainty $u\left(\mathrm{~m}_{\mathrm{i}}\right)$ associated with the respective weighings of masses $\mathrm{m}_{0}, \mathrm{~m}_{1}, \mathrm{~m}_{2}$ and $\mathrm{m}_{3}$ is considered equal to a third $(\mathrm{k}=3)$ of the permissible maximum error (PME) for the measured mass, assumed in the present study to be $1 \mathrm{mg}$, added to the repeatability error determined by performing 3 measurements for each mass:

$$
u\left(\mathrm{~m}_{\mathrm{i}}\right)=\left[\left(\frac{P M E_{m}}{\sqrt{3}}\right)^{2}+\left(\frac{\mathrm{s}\left(\mathrm{m}_{\mathrm{i}}\right)}{\sqrt{3}}\right)^{2}\right]^{\frac{1}{2}}
$$

The uncertainty associated with the experimental measurement of sample density is then defined as:

$$
\begin{aligned}
\mathrm{u}\left(\rho_{\text {sample }}\right)= & {\left[\left(\frac{\rho_{\text {sample }} \cdot \mathrm{u}(\mathrm{T})}{\rho_{\mathrm{eth}} \cdot(T+273 \cdot 15)}\right)^{2}+\left(\rho_{\mathrm{eth}} \cdot \frac{\left(\mathrm{m}_{3}-\mathrm{m}_{1}\right)}{\left(\mathrm{m}_{2}-\mathrm{m}_{0}\right)}\right)^{2} \cdot\left(\frac{2 \cdot P M E_{m}^{2}+s\left(m_{1}\right)^{2}+s\left(m_{3}\right)^{2}}{3 \cdot\left(\mathrm{m}_{3}-\mathrm{m}_{1}\right)^{2}}\right.\right.} \\
& \left.\left.+\frac{2 \cdot P M E_{m}^{2}+s\left(m_{2}\right)^{2}+s\left(m_{0}\right)^{2}}{3 \cdot\left(\mathrm{m}_{2}-\mathrm{m}_{0}\right)^{2}}\right)\right]^{\frac{1}{2}}
\end{aligned}
$$

It should be noted that correlated errors, associated with mass measurements performed on the same scale have been ignored, since they represent less than $1 \%$ of the overall uncertainty (determined on one typical experimental data set).

The uncertainty for the mean sample density value is computed by taking into account the dispersion and the mean value of the uncertainties associated with $\mathrm{N}$ experimental measurements:

$$
u_{c}\left(\bar{\rho}_{\text {sample }}\right)=\sqrt{\left(\frac{\mathrm{s}\left(\rho_{\text {sample }}\right)}{\sqrt{N}}\right)^{2}+\frac{1}{\mathrm{~N}} \sum_{\mathrm{s}=1}^{\mathrm{N}} \mathrm{u}\left(\rho_{\text {sample }}\right)^{2}}
$$

where $\mathrm{s}\left(\rho_{\text {sample }}\right)$, is the standard deviation associated with $\mathrm{N}$ measurements of sample density.

The confidence interval with a probability level of $95 \%$ is determined by multiplying the uncertainty by a weighting factor $\mathrm{k}=2$ :

$$
\operatorname{IC}\left(\overline{\rho_{\text {sample }}}\right)=2 \cdot u_{c}\left(\overline{\rho_{\text {sample }}}\right)
$$




\section{Annex II: Statistical analysis of experimental values of soot density}

Considering several measurements, $\mathrm{N}$, of sample density, the dispersion of the corresponding densities was compared using a $\chi^{2}$ test.

For this purpose, the standard deviation associated with $\mathrm{N}$ measurements of sample density $\left(\rho_{\text {sample }}\right)$ was calculated first. The discriminant factor $\mathrm{K} \chi^{2}$ of the $\chi^{2}$ test was then introduced as the ratio between this standard deviation and the mean sample density value $\overline{\rho_{\text {sample }}}$ :

$$
K_{\chi 2}=\frac{\mathrm{s}\left(\rho_{\text {sample }}\right)}{\overline{\rho_{\text {sample }}}}
$$

Finally, considering a probability of $95 \%$ (5\% of chance of drawing a false conclusion) the $\mathrm{K} \chi^{2}$ factor was compared with values reported below in the $\chi^{2}$ reference table associated with $\mathrm{N}$ measurements (or degrees of freedom).

The test is considered to be successful if $\mathrm{K}_{\mathrm{X}-2}$ is lower than the value reported in the $\chi^{2}$ table, confirming that the dispersion of the $\mathrm{N}$ values of sample density is fully explained by the measurement uncertainty and is not due to any heterogeneity of the sample.

Table AII-1: $\chi^{2}$ values as a function of probability $\mathrm{P}$ and degrees of freedom $v$ (from Neuilly \& CETAMA, 1998)

\begin{tabular}{|c|c|c|c|c|c|c|c|c|c|c|c|c|c|}
\hline$v \quad P$ & 0.005 & 0.01 & 0.025 & 0.05 & 0.1 & 0.25 & 0.5 & 0.75 & 0.9 & 0.95 & 0.975 & 0.99 & 0.995 \\
\hline 1 & 0.0000 & 0.0002 & 0.0010 & 0.0039 & 0.0158 & 0.102 & 0.455 & 1.32 & 2.71 & 3.84 & 5.02 & 6.63 & 7.88 \\
\hline 2 & 0.0100 & 0201 & 0.0506 & 0.103 & 0.211 & 0.575 & 1.39 & 2.77 & 4.61 & 5.99 & 7.38 & 9.21 & 10.6 \\
\hline 3 & 0.0717 & 0.115 & 0.216 & 0.352 & 0.584 & 1.21 & 2.37 & 4.11 & 6.25 & 7.81 & 9.35 & 11.3 & 12.8 \\
\hline 4 & 0.207 & 0.297 & 0.484 & 0.711 & 1.06 & 1.92 & 3.36 & 5.39 & 7.78 & 9.49 & 11.1 & 13.3 & 14.9 \\
\hline 5 & 0.412 & 0.554 & 0.831 & 1.15 & 1.61 & 2.67 & 4.35 & 6.63 & 9.24 & 11.1 & 12.8 & 15.1 & 16.7 \\
\hline 6 & 0.676 & 0.872 & 1.24 & 1.64 & 2.20 & 3.45 & 5.35 & 7.84 & 10.6 & 12.6 & 14.4 & 16.8 & 18.5 \\
\hline 7 & 0.989 & 1.24 & 1.69 & 2.17 & 2.83 & 4.25 & 6.35 & 9.04 & 12.0 & 14.1 & 16.0 & 18.5 & 20.3 \\
\hline 8 & 1.34 & 1.65 & 2.18 & 2.73 & 3.49 & 5.07 & 7.34 & 10.2 & 13.4 & 15.5 & 17.5 & 20.1 & 22.0 \\
\hline 9 & 1.73 & 2.09 & 2.70 & 3.33 & 4.17 & 5.90 & 8.34 & 11.4 & 14.7 & 16.9 & 19.0 & 21.7 & 23.6 \\
\hline 10 & 2.16 & 2.56 & 3.25 & 3.94 & 4.87 & 6.74 & 9.34 & 12.5 & 16.0 & 18.3 & 20.5 & 23.2 & 25.2 \\
\hline 11 & 2.60 & 3.05 & 3.82 & 4.57 & 5.58 & 7.58 & 10.3 & 13.7 & 17.3 & 19.7 & 21.9 & 24.7 & 26.8 \\
\hline 12 & 3.07 & 3.57 & 4.40 & 5.23 & 6.30 & 8.44 & 11.3 & 14.8 & 18.5 & 21.0 & 23.3 & 26.2 & 28.3 \\
\hline 13 & 3.57 & 4.11 & 5.01 & 5.89 & 7.04 & 9.30 & 12.3 & 16.0 & 19.8 & 22.4 & 24.7 & 27.7 & 29.8 \\
\hline 14 & 4.07 & 4.66 & 5.63 & 6.57 & 7.79 & 10.2 & 13.3 & 17.1 & 21.1 & 23.7 & 26.1 & 29.1 & 31.3 \\
\hline 15 & 4.60 & 5.23 & 6.26 & 7.26 & 8.55 & 11.0 & 14.3 & 18.2 & 22.3 & 25.0 & 27.5 & 30.6 & 32.8 \\
\hline 16 & 5.14 & 5.81 & 6.91 & 7.96 & 9.31 & 11.9 & 15.3 & 19.4 & 23.5 & 26.3 & 28.8 & 32.0 & 34.3 \\
\hline 17 & 5.70 & 6.41 & 7.56 & 8.67 & 10.1 & 12.8 & 16.3 & 20.5 & 24.8 & 27.6 & 30.2 & 33.4 & 35.7 \\
\hline 18 & 6.26 & 7.01 & 8.23 & 9.39 & 10.9 & 13.7 & 17.3 & 21.6 & 26.0 & 28.9 & 31.5 & 34.8 & 37.2 \\
\hline 19 & 6.84 & 7.63 & 8.91 & 10.1 & 11.7 & 14.6 & 18.3 & 22.7 & 27.2 & 30.1 & 32.9 & 36.2 & 38.6 \\
\hline 20 & 7.43 & 8.26 & 9.59 & 10.9 & 12.4 & 15.5 & 19.3 & 23.8 & 28.4 & 31.4 & 34.2 & 37.6 & 40.0 \\
\hline 21 & 8.03 & 8.90 & 10.3 & 11.6 & 13.2 & 16.3 & 20.3 & 24.9 & 29.6 & 32.7 & 35.5 & 8.9 & 41.4 \\
\hline 22 & 8.64 & 9.54 & 11.0 & 12.3 & 14.0 & 17.2 & 21.3 & 26.0 & 30.8 & 33.9 & 36.8 & 40.3 & 42.8 \\
\hline 23 & 9.26 & 10.2 & 11.7 & 13.1 & 14.8 & 18.1 & 22.3 & 27.1 & 32.0 & 35.2 & 38.1 & 41.6 & 44.2 \\
\hline 24 & 9.89 & 10.9 & 12.4 & 13.8 & 15.7 & 19.0 & 23.3 & 28.2 & 33.2 & 36.4 & 39.4 & 43.0 & 45.6 \\
\hline 25 & 10.5 & 11.5 & 13.1 & 14.6 & 16.5 & 19.9 & 24.3 & 29.3 & 34.4 & 37.7 & 40.6 & 44.3 & 46.9 \\
\hline 26 & 11.2 & 12.2 & 13.8 & 15.4 & 17.3 & 20.8 & 25.3 & 30.4 & 35.6 & 38.9 & 41.9 & 45.6 & 48.3 \\
\hline 27 & 11.8 & 12.9 & 14.6 & 16.2 & 18.1 & 21.7 & 26.3 & 31.5 & 36.7 & 40.1 & 43.2 & 47.0 & 49.6 \\
\hline 28 & 12.5 & 3.6 & 15.3 & 16.9 & 18.9 & 22.7 & 27.3 & 32.6 & 37.9 & 41.3 & 44.5 & 48.3 & 51.0 \\
\hline 29 & 13.1 & 14.3 & 16.0 & 17.7 & 19.8 & 23.6 & 28.3 & 33.7 & 39.1 & 42.6 & 45.7 & 49.6 & 52.3 \\
\hline 30 & 13.8 & 15.0 & 16.8 & 18.5 & 20.6 & 24.5 & 29.3 & 34.8 & 40.3 & 43.8 & 47.0 & 50.9 & 53.7 \\
\hline 40 & 20.7 & 22.2 & 24.4 & 26.5 & 29.1 & 33.7 & 39.3 & 45.6 & 51.8 & 55.8 & 59.3 & 63.7 & 66.8 \\
\hline 50 & 28.0 & 29.7 & 32.4 & 34.8 & 37.7 & 42.9 & 49.3 & 56.3 & 63.2 & 67.5 & 71.4 & 76.2 & 79.5 \\
\hline 60 & 35.5 & 37.5 & 40.5 & 43.2 & 46.5 & 52.3 & 59.3 & 67.0 & 74.4 & 79.1 & 83.3 & 88.4 & 92.0 \\
\hline 70 & 43.3 & 45.4 & 48.8 & 51.7 & 55.3 & 61.7 & 69.3 & 77.6 & 85.5 & 90.5 & 95.0 & 100.4 & 104.2 \\
\hline 80 & 51.2 & 53.5 & 57.2 & 60.4 & 64.3 & 71.1 & 79.3 & 88.1 & 96.6 & 101.9 & 106.6 & 112.3 & 116.3 \\
\hline 90 & 59.2 & 61.8 & 65.6 & 69.1 & 73.3 & 80.6 & 89.3 & 98.6 & 107.6 & 113.1 & 118.1 & 124.1 & 128.3 \\
\hline 100 & 67.3 & 70.1 & 74.2 & 77.9 & 82.4 & 90.1 & 99.3 & 109.1 & 118.5 & 124.3 & 129.6 & 135.8 & 140.2 \\
\hline$P$ & 0.005 & 0.01 & 0.025 & 0.05 & 0.1 & 0.25 & 0.5 & 0.75 & 0.9 & 0.95 & 0.975 & 0.99 & 0.995 \\
\hline
\end{tabular}


Annex III: raw values of sample true density measured in accordance with ISO 787-23 and results of their statistical analysis

\begin{tabular}{|c|c|c|c|c|c|c|c|c|c|c|c|}
\hline \multirow{2}{*}{$\underline{\text { Source }}$} & \multirow{2}{*}{\multicolumn{2}{|c|}{$\underline{\text { Fuel }}$}} & \multicolumn{8}{|c|}{ True density values $\left(\mathrm{kg} / \mathrm{m}^{3}\right)+/-$ Uncertainty $(\mathrm{k}=1)$} & \multirow{2}{*}{$\frac{\text { Result }}{\chi^{2} \text { test }}$} \\
\hline & & & $\# 1$ & $\# 2$ & $\# \mathbf{3}$ & $\# 4$ & $\# \mathbf{5}$ & \#6 & $\# 7$ & $\underline{\# 8}$ & \\
\hline \multirow{7}{*}{ References } & \multicolumn{2}{|c|}{ Glass } & $2432+/-3$ & $2388+/-3$ & $2367+/-3$ & - & - & - & - & - & FALSE \\
\hline & \multicolumn{2}{|c|}{$\mathrm{Al}_{2} \mathrm{O}_{3}$} & $3957+/-4$ & $3906+/-4$ & $3933+/-4$ & $3953+/-4$ & - & - & - & - & TRUE \\
\hline & \multicolumn{2}{|c|}{ LB 101} & $1759+/-2$ & $1674+/-2$ & $1718+/-2$ & - & - & - & - & - & FALSE \\
\hline & \multicolumn{2}{|c|}{ Printex 90} & $1788+/-2$ & $1788+/-2$ & $1777+/-2$ & $1815+/-2$ & $1807+/-3$ & $1768+/-2$ & - & - & TRUE \\
\hline & \multicolumn{2}{|c|}{ Printex 25} & $1891+/-2$ & $1882+/-2$ & $1849+/-2$ & $1884+/-2$ & $1885+/-2$ & - & - & - & TRUE \\
\hline & \multicolumn{2}{|c|}{ Glassy C. } & $1382+/-2$ & $1383+/-2$ & $1396+/-2$ & $1398+/-2$ & $1415+/-2$ & $1437+/-2$ & - & - & FALSE \\
\hline & \multicolumn{2}{|c|}{ CAST $16.2 \%$ OC/TC } & $1526+/-5$ & $1752+/-5$ & $1614+/-3$ & - & - & - & - & - & FALSE \\
\hline \multirow{7}{*}{$\begin{array}{l}\text { Diffusion } \\
\text { Flame } \\
\text { (cone } \\
\text { calorimeter) }\end{array}$} & \multicolumn{2}{|c|}{ Acetylene $\left(\mathrm{C}_{2} \mathrm{H}_{2}\right)(\mathrm{BANCO})$} & $1734+/-3$ & $1704+/-3$ & - & - & - & - & - & - & FALSE \\
\hline & \multicolumn{2}{|c|}{ Toluene $\left(\mathrm{C}_{7} \mathrm{H}_{8}\right) 450$ (BANCO) } & $1610+/-4$ & $1419+-/ 5$ & - & - & - & - & - & - & FALSE \\
\hline & \multicolumn{2}{|c|}{ Toluene $\left(\mathrm{C}_{7} \mathrm{H}_{8}\right) 100$ (BANCO) } & $1472+/-8$ & $1404+/-5$ & $1574+/-4$ & - & - & - & - & - & FALSE \\
\hline & \multicolumn{2}{|c|}{ PMMA $\left(\mathrm{C}_{5} \mathrm{H}_{8} \mathrm{O}_{2}\right) 450(\mathrm{BANCO})$} & $1772+/-4$ & $1671+/-4$ & $1644+/-3$ & $1616+/-3$ & $1533+/-5$ & - & - & - & FALSE \\
\hline & \multicolumn{2}{|c|}{ PMMA $\left(\mathrm{C}_{5} \mathrm{H}_{8} \mathrm{O} 2\right) 100(\mathrm{BANCO})$} & $1494+/-7$ & $1489+/-5$ & - & - & - & - & - & - & TRUE \\
\hline & \multicolumn{2}{|c|}{ 2/3 PMMA + 1/3 PVC (BANCO) } & $1281+/-6$ & $1340+/-8$ & $1322+/-96$ & - & - & - & - & - & TRUE \\
\hline & \multicolumn{2}{|c|}{ TBP / TPH (PARIS) } & $1495+/-2$ & $1573+/-2$ & - & - & - & - & - & - & FALSE \\
\hline \multirow{7}{*}{$\begin{array}{l}\text { Real } \\
\text { scale } \\
\text { fire }\end{array}$} & \multicolumn{2}{|c|}{ Electrical elements (BANCO) } & $1762+/-6$ & - & - & - & - & - & - & - & - \\
\hline & \multicolumn{2}{|c|}{ Electrical cabinet (DIVA) } & $1681+/-2$ & $1692+/-2$ & $1644+/-2$ & - & - & - & - & - & FALSE \\
\hline & \multicolumn{2}{|c|}{ Electrical cables (CFS) } & $1867+/-2$ & $2050+/-2$ & $2024+/-2$ & $2016+/-2$ & $2041+/-2$ & - & - & - & FALSE \\
\hline & \multicolumn{2}{|c|}{ Electrical cable with PVC (CORE) } & $1812+/-6$ & $1723+/-7$ & $1760+/-6$ & $1777+/-5$ & - & - & - & - & TRUE \\
\hline & \multicolumn{2}{|c|}{ Hydraulic oil (FES) } & $1578+/-6$ & $1382+/-4$ & $1757+/-6$ & $1800+/-6$ & $1806+/-4$ & - & - & - & FALSE \\
\hline & \multicolumn{2}{|c|}{ Gloves box (SATURNE) } & $1641+/-5$ & $1687+/-2$ & $1811+/-9$ & $2006+/-11$ & $1746+/-4$ & $1717+/-3$ & $1694+/-3$ & $1688+/-3$ & FALSE \\
\hline & Gloves 1 & (DIVA) & $2063+/-2$ & $2032+/-2$ & $2132+/-2$ & $2073+/-2$ & $2042+/-2$ & - & - & - & FALSE \\
\hline & Fuel & Temperature & & & & & & & & & \\
\hline & Gloves box & $120^{\circ} \mathrm{C}$ & $1650+/-3$ & $1582+/-2$ & $1748+/-3$ & - & - & - & - & - & FALSE \\
\hline & (SATURNE) & $240^{\circ} \mathrm{C}$ & $2120+/-4$ & $1545+/-3$ & $1636+/-3$ & - & - & - & - & - & FALSE \\
\hline Temperature & Hydraulic oil & $120^{\circ} \mathrm{C}$ & $2043+/-4$ & $1722+/-4$ & $1628+/-4$ & - & - & - & - & - & FALSE \\
\hline & $(\mathrm{FES})$ & $240^{\circ} \mathrm{C}$ & $1822+/-4$ & $1885+/-7$ & $1462+/-6$ & $1548+/-5$ & $1540+/-5$ & - & - & - & FALSE \\
\hline Effect & PMMA 450 & $120^{\circ} \mathrm{C}$ & $1630+/-4$ & $1560+/-4$ & $1574+/-12$ & - & - & - & - & - & TRUE \\
\hline & (BANCO) & $240^{\circ} \mathrm{C}$ & $1774+/-5$ & $1507+/-6$ & $1672+/-6$ & $1600+/-5$ & - & - & - & - & FALSE \\
\hline & Toluene 100 & $120^{\circ} \mathrm{C}$ & $1381+/-5$ & $1232+/-4$ & $1526+/-4$ & - & - & - & - & - & FALSE \\
\hline & (BANCO) & $240^{\circ} \mathrm{C}$ & $1393+/-4$ & $1458+/-4$ & $1493+/-8$ & - & - & - & - & - & FALSE \\
\hline
\end{tabular}




\section{Annex IV: Potential effect of organic fraction dissolution in ethanol}

In order to evaluate the magnitude of this bias, we performed EC-OC measurements for samples suspected to be the most sensitive to organic fraction dissolution during centrifugation in ethanol. After this treatment, samples were then dried in a furnace at $40^{\circ} \mathrm{C}$ for 48 hours and EC-OC measurements were then performed. Figure A1 presents a comparison between EC-OC before and after this treatment. The influence appears to be limited for most samples and agreement between the two analyses could be reported in a $95 \%$ confidence interval of $40 \%$ of the OC/TC ratio. To take into account the potential effect of the soluble organic fraction (SOF) being dissolved in ethanol, this confidence interval for $40 \%$ has been reported in Figure 3.

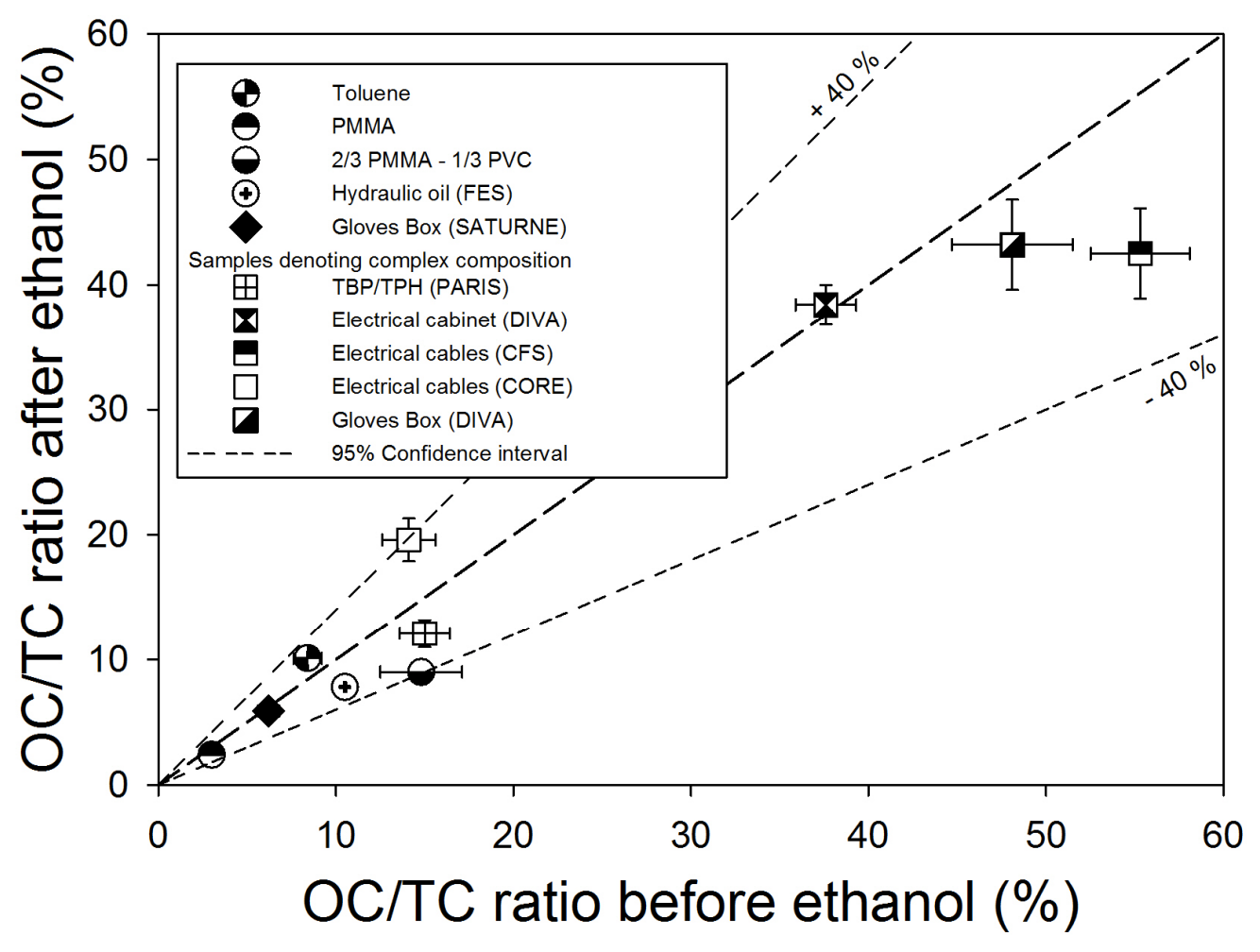

Figure A1: comparison of OC/TC ratio before and after ethanol treatment 
Annex V: Evolution of the $\mathrm{OC}$ fraction as a function of the $\mathrm{EC} / \mathrm{OC}$ analysis temperature

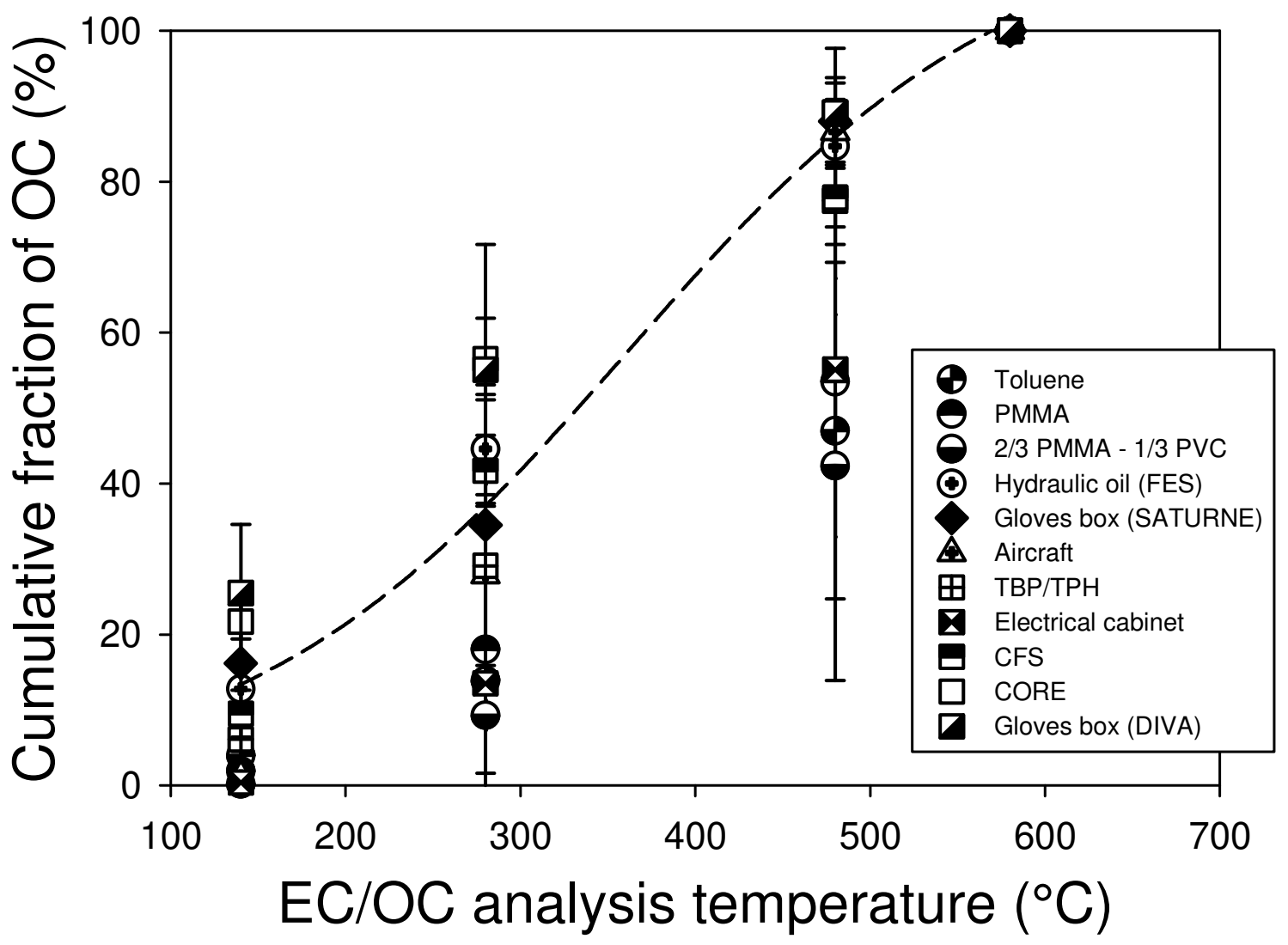

Figure A2: evolution of the cumulative mass fraction of $\mathrm{OC}$ as a function of $\mathrm{EC} / \mathrm{OC}$ analysis temperature 


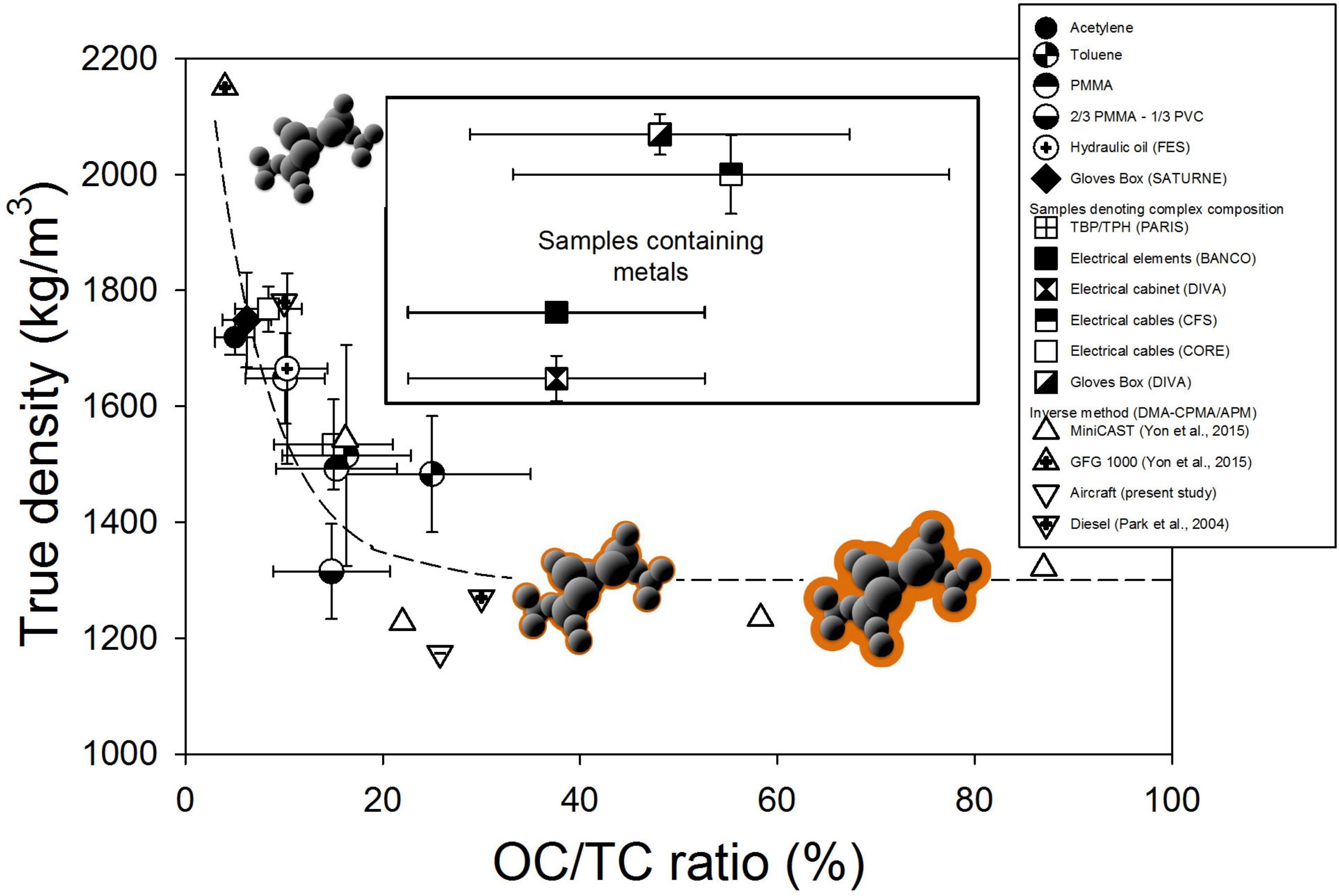

